\title{
The Yin and Yang of the Bone
} Marrow Microenvironment: Pros and Cons of Mesenchymal Stromal Cells in Acute Myeloid Leukemia

\author{
Marilena Ciciarello ${ }^{*}$, Giulia Corradi ${ }^{1}$, Federica Loscocco ${ }^{2}$, Giuseppe Visani ${ }^{2}$, \\ Federica Monaco ${ }^{2}$, Michele Cavo ${ }^{1,3}$, Antonio Curti ${ }^{3+}$ and Alessandro Isidori ${ }^{2+}$ \\ ${ }^{1}$ Department of Experimental, Diagnostic and Specialty Medicine, Institute of Hematology "L. \& A. Seràgnoli", University of \\ Bologna, S. Orsola-Malpighi Hospital, Bologna, Italy, ${ }^{2}$ Hematology and Stem Cell Transplant Center, AORMN Hospital, \\ Pesaro, Italy, ${ }^{3}$ Department of Hematology and Oncology, Institute of Hematology "L. and A. Seràgnoli", University Hospital \\ S.Orsola-Malpighi, Bologna, Italy
}

OPEN ACCESS

Edited by:

Onder Alpdogan,

Thomas Jefferson University,

United States

Reviewed by:

Leland Metheny,

University Hospitals of Cleveland,

United States

Sarah Wall,

The Ohio State University,

United States

${ }^{*}$ Correspondence:

Marilena Ciciarello

marilena.ciciarello2@unibo.it

tThese authors share the senior authorship

Specialty section This article was submitted to Hematologic Malignancies,

a section of the journal

Frontiers in Oncology

Received: 01 July 2019 Accepted: 10 October 2019 Published: 25 October 2019

Citation:

Ciciarello M, Corradi G, Loscocco F Visani G, Monaco F, Cavo M, Curti A and Isidori A (2019) The Yin and Yang

of the Bone Marrow

Microenvironment: Pros and Cons of Mesenchymal Stromal Cells in Acute

Myeloid Leukemia.

Front. Oncol. 9:1135

doi: 10.3389/fonc.2019.01135
Mesenchymal stromal cells (MSCs) have, for a long time, been recognized as pivotal contributors in the set up and maintenance of the hematopoietic stem cell (HSC) niche, as well as in the development and differentiation of the lympho-hematopoietic system. MSCs also have a unique immunomodulatory capacity, which makes them able to affect, both in vitro and in vivo, the function of immune cells. These features, namely the facilitation of stem cell engraftment and the inhibition of lymphocyte responses, have both proven essential for successful allogeneic stem cell transplantation (allo-SCT), which remains the only curative option for several hematologic malignancies. For example, in steroid-refractory acute graft-vs. host disease developing after allo-SCT, MSCs have produced significant results and are now considered a treatment option. However, more recently, the other side of the MSC coin has been unveiled, because of their emerging role in creating a protective and immune-tolerant microenvironment able to support the survival of leukemic cells and affect the response to therapies. In this light, it has been proposed that the failure of current treatments to efficiently override the stroma-mediated protection of leukemic cells accounts for the high rate of relapse in acute myeloid leukemia, at least in part. In this review, we will focus on emerging microenvironment-driven mechanisms conferring a survival advantage to leukemic cells overt physiological HSCs. This body of evidence increasingly highlights the opportunity to consider tumor-microenvironment interactions when designing new therapeutic strategies.

Keywords: acute myeloid leukemia, mesenchymal stromal cells, bone marrow microenvironment, drug resistance, immunomodulation

\section{INTRODUCTION}

A "Mesenchymal stem cell-like" population was initially classified as a subpopulation of bone marrow (BM) cells with the ability to reconstitute ectopic BM following heterotopic transplantation $(1,2)$. This subpopulation showed rapid adherence to culture dishes and a fibroblast-like shape, which distinguished them from hematopoietic cells. In addition, this subpopulation retained the 
ability to form colonies, called colony-forming unit fibroblasts (CFU-Fs) (3), with the capacity to regenerate bone tissue in serial implants in vivo, suggesting a self-renewal and multilineage potential (4). Subsequent studies identified the role of the adherent cells obtained from long-term BM cultures in supporting hematopoietic cells (5). The hypothesis of a stem cell niche, with non-hematopoietic components regulating hematopoiesis, was born (6), although it took several more years to definitively accept this concept. In 1991, Caplan coined the definition of Mesenchymal Stem Cells for this adherent cell population (7). Nowadays, the term of Mesenchymal Stromal Cells (MSCs) seems more appropriate Indeed, the multi-lineage potential of a single MSC has not been fully proven, thus not all MSCs can be considered bona fide stem cells in vivo (8).

Since the first definition, the studies regarding MSC properties have advanced rapidly. Thus, beside the originally discovered function in hematopoiesis supporting ability, other talents have been revealed in vitro and in vivo. The physiological abilities of MSCs, as we will discuss below (YIN), have proven to be essentials for successful allogeneic stem cell transplantation in AML and to counteract the Graft versus host disease (GVHD) (YIN), but can also be exploited by malignant cells to their advantage (YANG). The BM microenvironment can be remodeled favoring malignant cell expansion and resistance to therapy, at the expense of normal hematopoiesis. Thus, the "Pros" of MSCs may become "Cons" in the malignant niche.

\section{THE YIN OF MSCS: MSC ROLE IN HEALTHY HEMATOPOIESIS AND IMMUNE MODULATION}

\section{MSC-Dependent Hematopoiesis Support}

MSCs represent one of the fundamental components of the hematopoietic niche $(9,10)$ (Figure 1A). In vivo, the niche provides a microenvironment which controls the maintenance, self-renewal, and differentiation of hematopoietic stem cells (HSCs), also regulating the release of mature progeny into the vascular system. In addition, the niche protects HSCs from stimuli which would exhaust the stem-cell reserves (11). MSCs actively contribute to the creation of the HSC niche. Indeed, when transplanted in mice, MSCs have been shown to differentiate into osteoblasts, pericytes, BM stromal cells, osteocytes, and endothelial cells, which all represent functional elements of the niche able to support hematopoiesis (12).

BM-MSCs also favor the engraftment and homing of HSCs in the BM of animals when co-transplanted (13-15). The capacity of MSCs to support hematopoiesis was demonstrated in vitro (16) and both direct cell-to-cell contact and release of soluble factors seem to be involved (17). Human MSCs produce a wide variety of cytokines favoring HSC quiescence or self-renewal, i.e., stem cell factor (SCF), stromal cell-derived factor (SDF-1), bone morphogenetic protein 4, transforming growth factor (TGF)- $\beta$, leukemia inhibitory factor (LIF), and other cytokines influencing more mature hematopoietic progenitors e.g., granulocyte macrophage colony-stimulating factor (GM-CSF), and granulocyte colony-stimulating factor (G-CSF) (16). MSCs also produce several interleukins (i.e., IL1, IL-6, IL-7, IL-8, 1L-11, IL-12, IL-14, IL-15). The importance of cell-to-cell contact has been suggested by the demonstration that $\mathrm{CD} 34^{+}$cells adhere to the MSC feeder layer, due to the expression of proteins such as cadherins, integrins, vascular cell adhesion molecule, and neural cell adhesion molecule 1 . This adhesion is essential to maintain primitive hematopoietic progenitors in culture (18). In vivo, different hematopoietic stem and progenitor cell subsets occupy distinct locations in the BM. Analysis of murine BM sections revealed that approximately $85 \%$ of HSCs are localized within sinusoidal blood vessels, suggesting the existence of a perivascular niche and its fundamental role in regulating HSC fate (19). On the contrary, $<20 \%$ of HSCs are located close to the endosteum (within $10 \mu \mathrm{m})(20,21)$. Current data indicate that HSCs localize in the BM according to the stage of differentiation (21), e.g., early lineage-committed progenitors reside preferentially in the endosteal niche (9). Given that the position of HSCs within the niche is critical, it is fundamental to define the features of stromal cells associated with the different locations. However, univocal surface markers for MSC identification and classification in vivo have not yet been found. Most of the available data were obtained in the mouse model. In 2006, Sugiyama et al. defined mesenchymal progenitors as the cells expressing an elevated level of the HSC maintenance protein, CXCL12 (SDF-1), the so called CXCL12-abundant reticular (CAR) cells. CAR cells are quite abundant in BM and are found in close contact with putative HSCs, in proximity to sinusoidal vessels and to endosteum (22). In 2007, another population of subendothelial osteoprogenitor cells was identified close to sinusoids. These cells were positive for the melanoma cell adhesion molecule $\left(\mathrm{CD} 146^{+}\right)$and show MSC activity, i.e., the ability to transfer the hematopoietic microenvironment upon heterotopic transplantation (23). Finally, Mendez-Ferrer et al. identified a putative mesenchymal population, expressing Nestin (Nestin $^{+}$MSCs), a protein typical of neural cells. Nestin ${ }^{+}$ MSCs show CFU-F content, multilineage differentiation, and self-renewal ability. Nestin ${ }^{+}$MSCs are closely associated with HSCs and reside in the perivascular area, and with a lower frequency in the immediate vicinity of the endosteum. In vivo, selective depletion of Nestin ${ }^{+}$MSCs reduces HSC number and BM homing of transplanted HSCs (24). Nestin ${ }^{+}$MSCs are less abundant than CAR cells and express CXCL12 as well. Thus, Nestin ${ }^{+}$MSCs may hold a more primitive phenotype compared to CAR cells (25). To date, is still under debate whether the different niche populations described in mice and therefore the spatial relationship between the different niche cells and HSCs are preserved in humans. As markers for human MSC identification, nerve growth factor receptor (CD271) and CD146 have been indicated. Indeed, CD271 ${ }^{+}$ cells are able to support hematopoiesis and to form CFUFs with tri-lineage differentiation potential in vitro (26), and CD146 defines a subset of $\mathrm{CD} 271^{+}$cell populations with different locations: endosteal cells $\left(\mathrm{CD}_{146^{-}}\right)$or perivascular cells $\left(\mathrm{CD} 146^{+}\right)(27)$, which express HSC maintenance genes $(28,29)$. These cells also express other markers such as CD105 and CD90 (30, 31). 


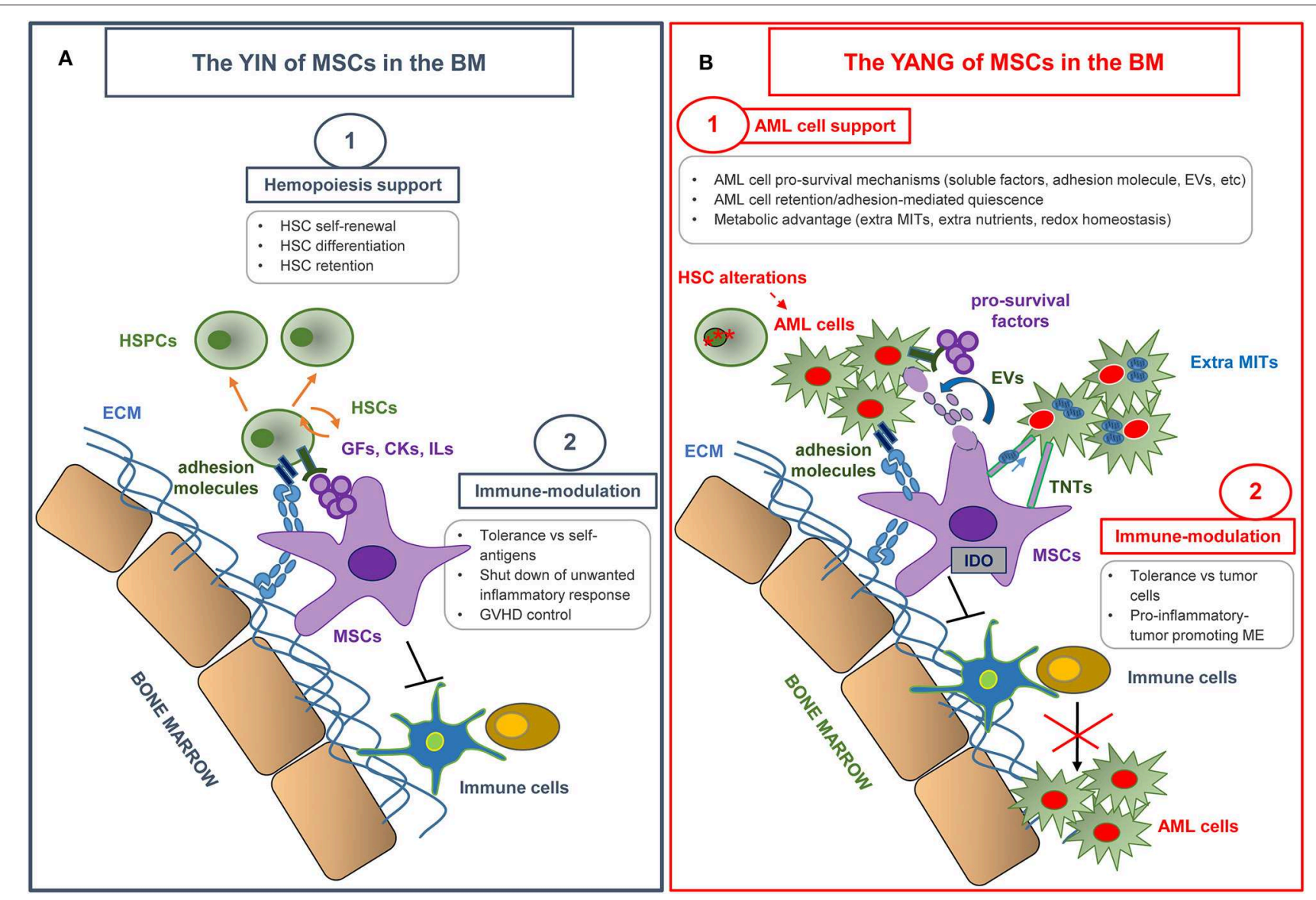

FIGURE 1 | The yin and yang of MSCs in the bone marrow microenvironment. (A) MSCs make a substantial contribution to the creation of the hematopoietic niche, and play an essential role in normal hematopoiesis by regulating hematopoietic stem cell (HSC) proliferation and differentiation. MSCs also display a unique immune regulation ability by inhibiting the activation, proliferation, and function of both adaptive and innate immune cells. MSC immunomodulatory properties have been extensively used in various clinical settings, in particular in graft vs. host disease (GVHD) control. HSPCs, hematopoietic stem and progenitor cells; ECM, extracellular matrix; GFs, growth factors; CKs, cytokines; ILs, interleukins. (B) MSCs have revealed an emerging role in creating a protective and immune-tolerant microenvironment able to support AML survival and to affect therapy response. The most relevant MSC-dependent processes nurturing a leukemia drug-resistant phenotype are outlined. AML, Acute Myeloid Leukemia; EVs, extra vesicles; TNTs, tunneling nanotubes; MITs, Mitochondria; ME, microenvironment.

\section{MSC Immunomodulatory Properties in vitro}

MSCs are considered to be hypoimmunogenic, because they express low levels of human leukocyte antigen class II (HLA-II) and co-stimulatory molecules including CD40, B7, CD80, and CD86, and they do not stimulate alloreactive $\mathrm{T}$ lymphocyte responses in vitro $(32,33)$. Moreover, a well-described characteristic of MSCs is their immune regulation ability, which influences both adaptive and innate immunity (34) (Figure 1A). The immunomodulatory effect of MSCs relies on immunological conditions in the local microenvironment, where inflammatory surroundings influence MSC behavior. In particular, interferon (IFN) $-\gamma$ and tumor necrosis factor (TNF)- $\alpha$ play a key role in inducing the immunosuppressive ability of MSCs and in creating an immunosuppressive microenvironment. This effect is desirable to induce self-tolerance and to control a potentially harmful inflammatory response, but, as explained in detail below, it is deleterious when it suppresses the response against cancer cells.

MSCs influence the activity and functions of various immune cells both via soluble factors and cell-to-cell contact mechanisms. In vitro, autologous or allogeneic MSCs are able to inhibit T-cell proliferation induced by distinct stimuli, including mitogens, alloantigens, and CD3/CD28 mediated activation (3437). Interestingly, MSCs do not induce T-cell apoptosis, but favor their survival in a quiescent state, promoting the arrest of $\mathrm{T}$ cells in the G0/G1 phase of the cell cycle $(38,39)$. The inhibitory effect of MSCs on T cells also requires MSC-Tcell contact (40). The activation of toll-like receptor (TLR)3 and TLR-4, expressed on human BM-derived MSCs (41), induces pro-inflammatory signals and hampers the negative activity of MSCs on T-cell proliferation (42). In turn, MSCs could be polarized, depending on TLR activation, into different phenotypes: a pro-inflammatory MSC1 phenotype when TLR4primed, and an immunosuppressive MSC2 phenotype following 
TLR3 activation (43). Furthermore, MSCs affect T-cell cytokine production: murine MSCs induce a decrease of IFN- $\gamma$ production by T helper 1 (Th1) cells in vivo (44) and human MSCs increase IL-4 production by Th2 cells in vitro (34), skewing the phenotype from a pro-inflammatory to an anti-inflammatory state (11). As discussed in detail below, the suppressive activity of MSCs is in part mediated by indoleamine 2,3-dioxygenase (IDO)-1 expression and activity, stimulated in turn by IFN- $\gamma /$ TNF- $\alpha$ producing activated T cells $(45,46)$. Additionally, MSCs inhibit naïve Cytotoxic T lymphocyte (CTL)-mediated lysis, through the release of soluble factors. MSCs are not lysed by CTLs, suggesting the existence of a mechanism which allows MSCs to escape recognition by CTLs (47).

MSCs are able to induce regulatory $\mathrm{T}$ cells (Tregs) (34). In particular, MSC-exposed Tregs have increased immunosuppressive activity, compared to Tregs not precultured with MSCs. This effect is potentially due to the activation of programmed cell death 1 receptor (PD)-1 on Tregs and IL-10 production in MSC/Treg co-culture system (48). In addition, prostaglandin E2 (PGE2), TGF- $\beta$, and HLA-G5 expression in MSCs, as well as contact-dependent mechanisms, are responsible for MSC-mediated Treg induction (49, 50). MSCs can indirectly induce Tregs by inducing the production of IL-10 in dendritic cells (DCs), which in turn induces the Treg generation in vitro (34).

It has been shown that MSCs may block DC differentiation from peripheral or cord blood-derived precursors (51). Likewise, MSCs prevent the typical expression of surface markers such as CD80, CD86, and HLA-DR during DC maturation (52). MSCs affect mature DC function, inducing a decreased expression of major histocompatibility complex class II and other proteins and a decreased IL-2 production, which in turn alter antigen presenting cell (APC) activity of DCs (53). In addition, MSCs reduce TNF- $\alpha$ secretion by DCs and hence reduce their pro-inflammatory activity (34). The negative regulation of DCs, mediated by MSCs, is exerted through several mechanisms, including MSC secretions of IL-6 (54) and PGE2 (55). Recently, MSC-derived extracellular vesicles (EVs) have been reported to reduce the maturation and function of DCs (56).

MSCs are involved in the regulation of natural killer (NK) cells and macrophages. MSCs are able to block resting NK cell proliferation and cytotoxicity, whereas MSC effects on NK activated cells are less evident (57). In addition, MSCs inhibit cytolysis mediated by NK cells and their IFN- $\gamma$ production, through HLA-G5 secretion (49). It is noteworthy that IL-2 activated NKs, contrary to freshly isolated NKs, are able to lyse autologous and allogeneic MSCs (57). Finally, murine MSCs promote macrophage $\mathrm{M} 2$ polarization in vitro through activation of signal transducer and activator of transcription (STAT)3 and inhibition of nuclear factor kappa-light-chain-enhancer of activated B cells (NF- $\kappa \mathrm{B}$ ) (58). Human MSCs program macrophage plasticity, favoring the M2 phenotype through PGE2 release and altering macrophage metabolic status (59). In turn, M2 macrophages, contrary to their M1 counterpart, are able to induce MSC osteoblast differentiation, suggesting their particular role in regulating bone homeostasis (60). Interestingly, MSCs can recruit macrophages/monocytes into the inflammation site through the release of paracrine factors (61).

\section{MSC Immunomodulatory Properties in vivo}

Given their immunomodulatory properties, MSCs have been extensively used in the clinical setting in recent years. In some areas, such as chronic degenerative disorders, genetic diseases, and solid organ transplantation, treatment with MSCs is in the early phases of development. In other fields, such as steroid refractory acute GVHD (sr-aGVHD), MSCs have already produced significant results, and might be considered as a treatment option (Figure 1A). Immunomodulation through MSCs has some properties which make it particularly useful for the treatment of sr-aGVHD. In particular, it does not require donor-recipient matching, it is non-antigen specific and, last but not least, it is dependent on exposure to inflammation ("site specific") (62). Accordingly, MSCs have been widely tested as a salvage option to treat sr-aGVHD, and convincingly shown their effectiveness by improving overall survival (OS) of responding patients $(63,64)$. Despite encouraging results reported within the last 10 years, there is still an urgent requirement to find welldefined factors that can be used to predict treatment outcome at an early stage, in order to identify those patients more likely to respond and the most effective administration regimen. A better understanding of these matters would considerably optimize MSC treatment and help doctors to clearly establish the possible role of MSCs in the therapeutic management of GVHD (65). An exhaustive discussion of the clinical trials conducted up to now is not an objective of this review. The results of the most relevant clinical studies with MSCs for sr-aGVHD, conducted in the last 10 years, are reported in Table 1.

\section{THE YANG OF MSCs: MSC ROLE IN AML ONSET AND PROGRESSION}

AML and other myeloid malignancies have for a long time been considered exclusively driven by leukemic cell-intrinsic mechanisms, due to the discovery of critical driver mutations in HSCs $(71,72)$. Recently, the role of the microenvironment and BM stromal cells, including MSCs, gained attention as critical contributors to AML pathogenesis, persistence, and recurrence. Recent findings suggest that alterations, which first occur in the BM niche, can directly drive the dysfunction of HSCs, favoring leukemia initiation and progression in a niche-driven model of malignant transformation. Moreover, growing evidence highlights the ability of leukemic cells to profit from physiological signals and to shape BM niche cells (HSC-driven model), in order to create a self-reinforcing and more favorable niche, supporting malignant cells at the expense of normal hematopoiesis.

\section{Niche-Driven Mechanisms of Leukemogenesis}

The BM microenvironment exerts not only a bystander effect but also plays an active role in myeloid transformation. The genetic manipulation of specific stromal cell subsets is able to drive leukemogenesis in mice. In a first study, the targeted 
TABLE 1 | MSCs for GVHD.

\begin{tabular}{|c|c|c|c|c|}
\hline Study & N. of patients & Cell dose $\left(10^{6} / \mathrm{Kg}\right)$ & Response rate (\%) & Overall survival (\%) \\
\hline Resnick et al. (66) & 50 & 1.1 & & 25 (80 in responders) \\
\hline von Dalowski et al. (64) & 58 & 0.99 & 47 & 19 at 1 year \\
\hline Sánchez-Guijo et al. (68) & 25 & $\begin{array}{l}1 \\
4 \text { sequential doses (all 2) }\end{array}$ & 71 & $\mathrm{~N} / \mathrm{R}$ \\
\hline
\end{tabular}

deletion of the Dicer I, ribonuclease III (Dicer I), in a welldefined population of mesenchymal progenitors recapitulates features of human myelodysplastic syndrome (MDS), including the propensity to develop into AML (73). The loss of Dicer $I$ results in a decrease of the SBDS ribosome maturation factor ( $S b d s)$ expression in mesenchymal/osteoprogenitor cells. $S B D S$ encodes for a protein involved in ribosomal maturation and its mutation has been identified in Shwachman-Diamond syndrome (SDS), characterized by BM failure with a high risk of developing AML (73). MSCs isolated from MDS patients show a lower expression of DICER I and SBDS (74). Furthermore, mesenchymal progenitors devoid of the Sbds gene show increased secretion of damage associated molecular pattern (DAMP) molecules, S100A8 and S100A9, leading to mitochondria dysfunction and genotoxic stress in HSCs. A correlation was also found between the expression of the two DAMP molecules in MSCs isolated from MDS patients and the increased risk of these patients of developing AML (75).

The role of MSC-derived osteoprogenitors in AML has recently been highlighted. The activating mutation in the $\beta$ catenin gene in osteoprogenitor cells causes the activation of Notch signaling in HSCs, and impairs myeloid and lymphoid differentiation leading to the development of AML in mice. Interestingly, $38 \%$ of $\mathrm{MDS}$ and AML patients show an increase of $\beta$-catenin signaling in osteoblasts and of $\mathrm{NOTCH}$ signaling in HSCs $(76,77)$. Finally, activating mutations of the Tyrosine phosphatase SHP-2 (encoded by Ptpn11 gene) in MSCs and osteoprogenitors, already found in Noonan syndrome and associated with an increased risk of leukemic transformation, induce juvenile myelomonocytic leukemia-like myeloproliferative neoplasm in mice (78).

A niche-driven mechanism of leukemia in humans is supported by the phenomenon of a donor cell-derived hematopoietic neoplasm, reported for AML, MDS, T-cell lymphoma, and chronic myeloid leukemia (CML). Indeed, in rare cases, donor-derived leukemia occurring in patients receiving $\mathrm{BM}$ transplantation may be completely different from the original leukemic clone. In the host, pre-existing BM niche alterations could initiate leukemogenesis in engrafted cells of donor origin $(79,80)$. In addition, a perturbation of those pathways, which we mentioned before as able to drive a niche-induced transformation in mice (i.e., Dicer1, sbds, S100A8/9, $\beta$-catenin), has been described in patients (73-76). Ex vivo expanded MSCs isolated from MDS and AML patients show several alterations, e.g., chromosomal aberrations in MSCs derived from MDS and AML patients have been reported in $30-70 \%$ of the samples. Surprisingly, in some patients, the cytogenetic abnormalities identified in MSCs are different from those detected in hematopoietic cells, isolated from the same patients $(81,82)$. Chromosomal and genetic alterations of MSCs have been correlated to specific gene-expression programs and disease subtypes, suggesting that the genetic susceptibility of MSCs can play an active role in the progression of MDS and AML (83). However, the functional meanings of these alterations are still under debate and conflicting results have been published. Several studies reported normal functionality including differentiation capacity, ability to support hematopoiesis in vitro, immunophenotype, expression of adhesion and extracellular matrix proteins (84-86). On the contrary, other studies revealed functional alterations of MSCs, including growth deficiency and altered osteogenic differentiation ability, and reduced capacity to support hematopoietic cells $(83,86-91)$. The secretome of MSCs is also altered in the leukemic BM $(87,92,93)$. In particular, it has been demonstrated that a subset of MSCs shows an increased expression of pro-inflammatory molecules e.g., C-C motif chemokine ligand 3 (CCL3), TNF, IL-8, IL-6, DAMPs, and a reduced expression of factors essential for HSC maintenance and differentiation e.g., CXCL12, KIT Ligand, and angiopoietin $1(28,61,75)$.

\section{HSC-Driven Mechanisms of Leukemogenesis Exploiting the BM Microenvironment}

Malignant HSCs can influence the composition and the functional status of the BM microenvironment. Medyouf et al. found that primary human MDS cells could instruct MSCs, isolated from healthy donors (HDs), toward an MDSlike behavior in vitro (94). Furthermore, in a patient-derived xenograft model, MDS cells need their disease-associated MSCs to propagate the disease in vivo, suggesting that both hematopoietic and stromal cells have a role in MDS (94). Recently, the remodeling of the niche, induced by AML cells, has been characterized. Similarly to MDS, healthy MSCs cultured in AML cell-conditioned medium showed a reduced osteogenic differentiation and proliferation ability (87). Among the mechanisms driving the remodeling of the niche, inflammation, a hallmark of cancer, seems to play a role. The ability to induce inflammation could potentially reflect specific "physiological" immune functions, still present in malignant cells 
(95). In an AML mouse model, it was observed that CCL3 produced by AML cells inhibits osteoblastic cells and bone demineralization. Interestingly, CCL3 mRNA is detected also in malignant cells isolated from AML patients (96).

AML cells are able to modify the transcriptome of MSCs. Indeed, leukemic stem cells (LSCs), unlike normal CD34 ${ }^{+}$cells, modulate in MSCs the expression of cell-cycle genes, cytokinerelated genes, and other genes, like CXCL12 and JAG-1, involved in cell-to-cell cross-talk (91).

Additionally, malignant cells can shape the niche through the release of EVs. EVs (e.g., exosomes and microvesicles) are new mediators in the intercellular communication network in various physiological and pathophysiological frameworks. EVs are produced starting from different cell types and perform different functions depending on their origins and cargoes. Indeed, EVs contain proteins, lipids, and nucleic acid, representing potential signal molecules to deliver to specific target cells $(97,98)$. Both primary AML cells and AML cell lines release EVs, carrying several coding and non-coding RNAs, relevant to AML pathogenesis. It has been demonstrated that the content of AML cell-derived EVs is able to modify stromal cell functions, regulating cellular pathways including the production of growth factors, metabolism, and immune response, all favoring AML cell survival (99-102). In vivo, AML-derived EVs mediate the $\mathrm{BM}$ remodeling leading to an increased number of mesenchymal stromal progenitors, osteoblast loss and downregulation of HSCsupporting factors in BM stromal cells. The disruption of EV secretion reduces leukemia progression in mice (103).

Kim and collaborators found that distinct patterns of MSC changes induced by AML cells characterize AML patients and are associated with a heterogeneous clinical course. Stromal remodeling in leukemic BM may potentially serve as a prognostic factor (91). All these mechanisms indicate a fundamental bidirectional interaction among malignant cells and surrounding microenvironment (83) with relevant consequences on AML onset and, as we will explain below, on disease development and outcome.

\section{Emerging Microenvironment-Driven Mechanisms of Drug Resistance}

Despite the introduction of new anti-leukemic agents and approaches, and the high rates of remission after induction therapy, treatment failure, and relapse are still major hurdles in AML. The persistence of AML cells after therapy, resulting in minimal residual disease (MRD), is the main factor responsible for AML relapse. In addition to cell-autonomous mutations (i.e., intrinsic factors), increasing evidence indicates that the BM microenvironment (i.e., extrinsic factors) may contribute to protect LSCs from being killed by chemotherapeutic agents, resulting in MRD persistence (104-107). Indeed, environmentmediated de novo drug resistance creates a transient state of malignant cell protection eventually leading to the selection and outgrowth of cells with an increasing level of acquired drug resistance (108). Here, we will describe the most relevant microenvironment-dependent processes underlying protection against chemotherapy, with a particular emphasis on new emerging mechanisms driven by MSCs to nurture a leukemia drug-resistant phenotype (Figure 1B).

\section{MSC-Dependent Multi-Drug Resistance Phenotype}

The tumor microenvironment can facilitate the establishment of a multi-drug resistance (MDR) phenotype in leukemic cells. Indeed, MDR may arise through different processes, including drug uptake and imbalance in cell survival/death signaling, but especially through the modulation of the adenosine triphosphatebinding cassette $(\mathrm{ABC})$ efflux transporter expression. The $\mathrm{ABC}$ transporter regulates the efflux of xenobiotics including chemotherapeutic drugs. In co-culture experiments, a subset of BM-derived stromal cells increased the expression of several ABC transporters in a myeloid leukemia cell line and protection against chemotherapy-induced apoptosis $(109,110)$. The adhesion of leukemic cells to the BM-microenvironment is also crucial for the persistence of MDR in AML (107).

\section{MSC-Dependent Pro-Survival Effect: Soluble Factors and Cell-to-Cell Contact}

The ultimate result of a successful cytotoxic treatment is the induction of apoptosis, a genetically determined process of programmed cell death. The BM microenvironment offers protection against cytotoxic agents, allowing the activation of anti-apoptotic signals and leading to enhanced cell survival and resistance to therapy. The activation of signals which inhibit apoptosis is correlated with a poor response to chemotherapy in AML (111-115).

BM stromal cells play a key role in the activation of prosurvival mechanisms. Earlier studies showed that stromal cells protect leukemic cells from apoptosis induced spontaneously, by serum deprivation or by drugs (116-119). It is still unclear whether the pro-survival effect of stromal cells on AML is either due to direct contact $(116,117,120)$ or to soluble factors secreted from stromal cells (118). Regarding the latter, compounds able to reduce IL- 6 production by BM stromal cells are cytotoxic for AML cells, but not for BM stromal cells themselves (121). Other growth factors affecting BM-mediated resistance to chemotherapy include TGF- $\beta$, basic fibroblast growth factor, and vascular endothelial growth factor $(122,123)$.

Both soluble factors and adhesion molecules activate prosurvival pathways and often interact with each other. SDF1/CXCL-12, constitutively expressed by both MSCs and MSCderived osteoblasts, could stimulate malignant cell survival (124). The SDF-1 receptor, CXCR4 is expressed by normal and malignant hematopoietic cells (125). Anti-CXCR4 or a CXCR4 antagonist decrease AML cell survival in vitro (126). Although SDF-1 has not been directly implicated in drugresistance, it could contribute by an indirect mechanism. Indeed, SDF-1/CXCR4 axis inhibition could override BM stromal cell protection to drug-induced apoptosis in $\operatorname{AML}(126,127)$. CXCR4 antagonists dramatically reduce AML load in mice previously engrafted with primary human AML without influencing the engraftment of normal hematopoietic progenitors (128), probably because tumor cells express higher levels of CXCR4 than normal cells (125). Furthermore, SDF-1 enhances integrin $\alpha 4 \beta 1$ (VLA)-4-mediated adhesion of tumor cells to extracellular 
matrix components (ECM), i.e., fibronectin and collagen, in the BM. Malignant hematopoietic cells adherent to ECM via VLA-4 showed an adhesion-mediated resistance to distinct types of chemotoxic agents (129). VLA-4-mediated adhesion promotes MRD in a mouse model of AML following cytarabine treatment. Anti-VLA4 antibodies reduce MRD and increase mice survival (107). Integrin ligation triggers activation of pro-survival pathways. Integrin-linked kinase interacts with $\beta$ integrins and activates PI3K/AKT-mediated pro-survival signaling in leukemia cells (120).

Whatever the upstream mechanism, the activation of prosurvival pathways results in the involvement of common targets. BCL2, a critical pro-survival factor, was significantly upregulated in leukemic cells in co-cultures with stromal cells $(118,130)$. In pre-clinical models, it has been demonstrated that the efficacy of BCL2 inhibitor venetoclax in vitro was attenuated by cytokines (i.e., soluble factors) produced by stromal cells (131, 132). Mechanistically, cytokines activate Janus kinase (JAK)/STAT signaling and decrease the expression of BCL-2 relative to the other BCL2 family members (i.e., BCLXL, MCL1, and BFL1). Accordingly, navitoclax, possibly targeting both BCL2 and BCLX, retains its cytotoxic activity also in the presence of the stroma.

As an alternative stroma-mediated pro-survival mechanism, it has been suggested that the microenvironment may contain factors (e.g., adhesion molecules) that can induce malignant cell quiescence contributing to protect them from the drugs targeting rapidly dividing cells. Homing to the niche is crucial for AML LSCs to maintain their stem cell properties, including quiescence. The adhesion molecule CD44, the receptor for hyaluronan, osteopontin, and other ECM molecules, is important for homing and engraftment of AML LSC in murine models. An anti-CD44 antibody inhibits AML LSC engraftment and alters their stem cell fate (133). While BM stromal cells exert their protective effect within the tumor microenvironment, it is likely that away from the niche this protection is no longer active. The mobilization of leukemic cells in the peripheral blood where they exit from dormancy and become subjected to the cytotoxicity of chemotherapeutic drugs could be considered a promising cell killing strategy. Disruption of CXCL-12/CXCR4 interactions with CXCR4 inhibitors efficiently blocks LSC homing to the $\mathrm{BM}$ niche and likely sensitizes leukemic cells to chemotherapy (125-128). Based on their ability to mobilize leukemia cells out of protective BM niches, different molecules, including CXCR4 antagonists, have been explored in combination with cytotoxic drugs (i.e., venetoclax).

Conversely, a pro-apoptotic stroma-dependent effect was observed in JAK2-inhibitor treatment (ruxolitinib). In this case, stroma-produced cytokines, such as G-CSF and GMCSF increased STAT-5 phosphorylation, a downstream target of JAKs, potentiating JAK inhibitor efficacy. When combined with venetoclax, the JAK2 inhibitor ruxolitinib demonstrated synergistic killing activity. This result was summarized in a systemic xenograft model of AML (132). Furthermore, AML cells prove more sensitive to drugs targeting rapidly dividing cells, such as taxanes and vinka alkaloids, in the presence of stroma-secreted soluble factors, probably due to their stimulating effect on cell proliferation (86).
At present, clinical studies with molecules directly targeting stroma are still under construction. Given the genetic diversity of $\mathrm{AML}$, and the complexity of the BM architecture, it will probably be necessary to design studies combining drugs with different targets. Theoretically, the major hurdle is still to find targets particular to the malignant cell population, in order to be able to reduce toxicity and preserve the functions and the properties of the healthy microenvironment. In this view, genomic profiling could be useful in identifying possible targets, also within stroma cells (134).

\section{MSC-Dependent Pro-Survival Effect: New Mechanisms}

In addition to cell-direct contact and soluble factors, the list of mechanisms accounting for MSC-dependent pro-survival factor transfer has progressively expanded.

EVs derived from MSCs (MSC-EVs) are able to vicariate MSCs themselves. Like MSCs, MSC-EVs are able to determine a decrease in pro-inflammatory responses including immune cell activation and oxidative stress (135). Moreover, EVs have been found to retain MSC therapeutic activities in vivo, including GVHD improvement (136). EV studies revealed a novel mechanism by which MSCs could play a pro-leukemic function. MSC-EVs act as paracrine factors and induce modifications in the recipient cells that could influence and inhibit proliferation of cancer cells in vitro and tumor progression in vivo, similar to MSCs (137-139). However, an opposite inhibitory effect on cancer was demonstrated in certain systems (137, 140, 141). Accordingly, EVs could have different effects on cancer cells depending on their content or source (i.e., if produced by normal or malignant MSCs). In particular, EVs derived from normal MSCs inhibit tumor cell proliferation in vitro and in vivo (142). Although the role of MSC-derived exosome signaling in AML has not yet been established, it has been demonstrated that exosomes derived from MSCs isolated from AML patients contained microRNAs able to influence gene regulatory networks in AML cells (143). In this light, the identification of microRNA and/or proteins that can be transferred from MSCs to leukemic cells represents a promising concept for the development of new therapeutic strategies to treat AML.

Tunneling nanotubes (TNTs) have been identified as a novel means for cell-to-cell communications (144-146). TNTs are filamentous actin-based structures, able to connect cells and to act as a route to transport organelles, proteins, and signal molecules, etc. $(146,147)$. TNTs have been characterized in both cell lines and primary AML cells (148). Interestingly, cytarabine significantly decreases TNTs, while Daunorubicin has no effect. The effect of drugs on TNT number could be an indicator of a different cell sensitivity to the microenvironment-mediated protection. By using a fluorescent tracking system, it was recently demonstrated that TNT signaling extends from MSCs toward AML cells; this could represent a route of mitochondria transfer (149) producing stromal-mediated drug resistance (150). These observations suggest that drugs targeting TNTs could potentially contribute to override the MSC-mediated tumor protection against apoptosis and to prevent drug resistance. 


\section{MSCs and Mitochondrial Metabolism Regulation}

Cancer cells consume high levels of glucose and the majority of them prefer glycolysis even in the presence of oxygen (Warburg effect). The prevailing concept is that the Warburg effect results from irreversible damage to the oxidative capacity of mitochondria in cancer cells. However, recent findings indicate that the Krebs cycle is intact in leukemia cells $(151,152)$, and utilizes substrates, such as glutamine and fatty acids, to generate intermediates for biosynthetic pathways and to counteract oxidative stress. In the absence of permanent alterations to the oxidative capacity of the cells, mitochondrial uncoupling (i.e., the abrogation of adenosine triphosphate (ATP) synthesis in response to mitochondrial potential) could mimic the Warburg effect. It has been demonstrated that in leukemia cells, MSCs increase the expression of uncoupling protein 2 (UCP2), a mitochondrial inner membrane protein that short circuits the electrochemical gradient generated by the mitochondrial respiration chain. Uncoupled mitochondria display a metabolic shift to the oxidation of carbon sources alternative to glucose, supported in part by fatty acid and glutamine metabolism. Uncoupled mitochondria are more resistant to cytotoxic insults, produce less reactive oxygen species (ROS) and block the activation of the intrinsic apoptotic pathway. Not all leukemic cells are uncoupled and exhibit increased aerobic glycolysis after co-cultures with MSCs $(153,154)$. Contrary to the Warburg hypothesis, LSCs rely on oxidative phosphorylation to generate ATP (155). LSCs, albeit variable from patient to patient and in some cases within the same patient, are considered the real perpetrators for the propagation of AML. Although the effect of MSCs on mitochondrial uncoupling in LSCs has not yet been evaluated, mitochondrial metabolism has progressively emerged as a putative point of vulnerability for LSCs. Indeed, the inhibition of mitochondrial metabolism selectively targets LSCs, which are metabolically inflexible, i.e., they are unable to shift to glycolysis when mitochondrial respiration is inhibited (152).

Cancer cells could use different strategies to acquire metabolites and organelles, including mitochondria, to build up ATP production. Consistently, it has been shown that AML cells present a higher number of mitochondria in comparison with normal HSCs $(156,157)$. Interestingly, extramitochondria derive from MSCs through a process of transfer that has not yet been defined, but which likely involve TNTs and/or endocytosis and requires cell-to-cell contact $(150,158)$. AML cells, through NADPH oxidase-2 (NOX2) activity, locally increase oxidative stress, pushing MSCs to increase mitochondria production (150). The extra-mitochondria are transferred to AML cells without any side effect on the metabolic health of MSCs through the activation of peroxisome proliferatoractivated receptor $\gamma$ coactivator (PGC)-1 $1 \alpha$, the master regulator of mitochondrial biogenesis, which is essential for AMLdirected mitochondrial transfer (159). Thus, AML cells with extra-functionally active mitochondria might gain a metabolic advantage, and possibly be relevant for chemo-resistance. Most types of chemotherapy exploit mechanisms involving the induction of oxidative stress. Thus, AML cells with the highest content of mitochondria could most likely survive after oxidative chemotherapy. Accordingly, it has been demonstrated that chemotherapy stimulates mitochondrial transfer (158).

Targeting mitochondria transfer could emerge as an intriguing approach to the development of therapeutic regimens able to tackle chemo-resistant metabolically advantaged AML cells. In support of this theory, normal CD34 ${ }^{+}$HSCs are less prone to receive extra-mitochondria, opening a window for a feasible target therapy with limited detrimental effects. In this context, NOX2 and PGC- $1 \alpha$ could be interesting targets, as (1) NOX2 knocked-down AML blasts have reduced mitochondrial respiration; (2) the NOX2 inhibitor decreases mitochondrial transfer and AML cell viability, whereas it is ineffective on normal HSCs, and (3) inhibition of PGC- $1 \alpha$ in BM-MSCs reduces mitochondria transport (159).

Moreover, NOX2 and PGC-1 $\alpha$ activity appear crucial for AML persistence and recurrence in vivo. In fact, NOX2 knocked-down AML mice show better OS with respect to the NOX2 wild type AML control (150), and PGC- $1 \alpha$ knocked-down BM-MSCs mice showed a reduced tumor volume compared with control mice (159). Last but not least, extra-mitochondria AML equipped cells could acquire additional anti-apoptotic proteins, also from the BCL-2 family, gaining a survival advantage and, possibly, resistance to standard therapy (160). Promising data, coming from the use of venetoclax, an anti-BCL-2, in elderly AML patients, might partly be exploited by venetoclax's effect on mitochondria and oxidative stress of AML cells (161).

\section{MSC-Dependent Nurturing Function}

Tumor cells are exposed to nutrient and oxygen-poor conditions. Thus, metabolic adaptation to stress condition and to increased nutrient demand is a crucial requirement for tumor cell survival and expansion. Several data suggest that there is a complex network of metabolic interactions involving malignant cells and their neighbors in the tumor microenvironment. In particular, it is becoming increasingly clear that cancer cells could induce stromal cells to produce metabolites and nutrients to feed their metabolism and gain a proliferative advantage. Among the stromal-produced nutrients, glutamine (GLN), albeit a nonessential amino acid, plays a key role in sustaining the metabolism of proliferating cells and regulating redox homeostasis. A variety of human cancer cell lines, including AML, have been shown to be highly dependent on GLN for proliferation and survival. In particular, AML cells are able to utilize GLN as an alternative carbon source for energy production (162). GLN deprivation or inhibition of Glutamine synthetase (GLS) cause cell growth inhibition and induce apoptosis in AML cells (163).

\section{MSC-Dependent Regulation of Redox Homeostasis}

Besides nurturing function, the BM microenvironment performs a fundamental role in regulating redox homeostasis of leukemia cells by contributing substrates to generate antioxidants. MSCs, by uncoupling mitochondria, contributed to the reduction of ROS and protection of AML cells from redox-induced damage $(153,164)$. Recent data have indicated that the leukemia microenvironment in the BM is hypoxic (165). Residing in a hypoxic region may contribute to protect leukemia cells from oxidative stress, including the stress generated by chemotherapy. 
Furthermore, it has been demonstrated that BM stromal cells contribute to the hypoxic adaptation of leukemic cells. BM-MSCs upregulate hypoxia inducible factor 1 subunit $\alpha$ (HIF-1 $\alpha)$ under hypoxic conditions through mTOR/AKT pathway activation. HIF- $1 \alpha$ is a key regulator of the cell response to hypoxia and, as a transcription factor, controls the expression of genes involved in energy metabolism, angiogenesis, apoptosis, and cell cycle. HIF- $1 \alpha$ induces the stabilization and the activation of the CXCL12 CXCR4 pathway, thus facilitating the recruitment and the retention of leukemic cells within the leukemic niche (166). HIF$1 \alpha$ up-regulation increases, in turn, the expression of the glucose transporter and drives leukemic cells to switch to glycolytic metabolism. This metabolic adaptation directly inhibits the mitochondrial apoptotic pathway (167). Thus, forced expression of HIF-1 $\alpha$ makes leukemic cells resistant to chemotherapy, whereas downregulation of HIF-1 $\alpha$ or inhibition of the mTOR pathway restore the chemosensitivity of leukemic cells (168).

\section{MSC-Dependent Immunosuppression and Inflammatory Pathways}

Among the multifaceted functions attributed to MSCs, immune modulation is the most relevant, from a clinical point of view. Selected pathways of tumor evasion from immune-surveillance, which could potentially lead to anti-cancer therapy resistance, can take place in the BM microenvironment. In solid tumors, it is now well-established that immune suppression mediated by the stromal environment contributes to cancer cell growth (169). However, a similar role for MSCs in AML is less clear. This is partially imputable to the poor characterization of the immunosuppressive and anti-inflammatory properties of MSCs derived from AML patients.

As discussed before, MSCs contribute to the immune responses. Many mediators, including IDO1, PGE2, HLAG5, IL-10, TGF- $\beta$, hepatocyte growth factor, heme oxygenase 1 and LIF, have been involved in the immunosuppressive activity of MSCs, at different levels. It is reasonable to assume that none of these factors alone could lead to a significant abrogation of the immune response. Rather, MSC-mediated immunoregulation is the result of the cumulative action displayed by several molecules simultaneously. Among these molecules, IDO1 performs an immunomodulatory activity in different settings, including AML (170). IDO enzymes catalyze the initial step in tryptophan degradation along the kynurenine pathway, which in turn inhibits T cell proliferation and induces T cell death (171). Thus, professional APCs but also MSCs upregulate IDO1 following inflammatory stimuli, mostly IFN$\gamma$ (45). MSCs, expressing IDO1, are able to activate Tregs and to induce T-cell differentiation of Tregs, thereby potentiating immunosuppression in the tumor microenvironment (172). Indeed, Tregs have been recognized as essential contributors in microenvironment immunomodulation and ultimately in helping leukemic cells to evade immune surveillance (173, 174). Data obtained in our lab demonstrated that AML cells, but not normal HSCs, expressed IDO1 (175) which mediates immune tolerance (176) and correlates with a poor clinical outcome (177). We further demonstrated that MSCs isolated from MDS and AML patients also up-regulated IDO1 following pro-inflammatory cytokine treatment to a similar extent with respect to MSCs isolated from HDs (our unpublished data), besides showing comparable immune-regulatory functions (86). However, others demonstrated that AML-derived MSCs are more highly immunosuppressive/anti-inflammatory than those derived from HDs (93). Leukemic cells originate and grow in the immunosuppressive Treg-rich BM microenvironment and are thus protected against the active immune response. On the one hand, immune-modulation could also be exacerbated within an inflamed tumor microenvironment. Inflammatory signals are produced, as mentioned before, both by AML cells and MSCs in the leukemic microenvironment. In particular, TNF- $\alpha$ is upregulated in MSCs after co-culture with leukemic cells (178). Thus, TNF- $\alpha$, indicated as crucial in all steps of hematologic malignancies $(179,180)$, may contribute to the generation of an inflammatory niche able to favor tumor growth and immune suppression. On the other hand, the production of an anti-inflammatory/immunosuppressive cytokine IL-10 by MSCs has been indicated as a negative prognostic factor in AML patients, suggesting a dual role of inflammation in the immune response (93). Furthermore, the increase in the MSCsecreted inflammatory cytokine IL- 6 could have opposite effects on immunosuppression. While IL- 6 has been involved in the inhibition of DC differentiation, decreasing the stimulatory effect of DCs on T cells $(53,54)$, the secretion of IL- 6 by MSCs has been shown to promote anti-tumor adaptive immunity by increasing T lymphocyte trafficking in the tumor microenvironment (181).

Finally, the effect of chemotherapy in the leukemic microenvironment partly relies on the induction of inflammatory modifications, including an increase in serum inflammatory cytokines, thus chemotherapy may lead to the upregulation of IDO1 expression on MSCs, exacerbating an immune tolerant environment. Besides IDO1, the induction of inducible nitric oxide synthase by MSCs and the production of nitric oxide (NO) were shown to play a major role in immunosuppression in murine systems (182-184). However, some data have been published supporting a regulatory role of $\mathrm{NO}$ production in MSC-induced immune suppression also in hematological malignancies (178).

All together, these changes in the MSC-dependent inflammatory status of the microenvironment can collectively result in immune modulation and could contribute to tumor progression and drug-resistance within the BM niche.

\section{CONCLUSIONS}

Until recently, AML research was focused on the identification of HSC-autonomous and disease-specific genetic events leading to malignant transformation. However, the contribution of the BM microenvironment has gained increasing attention, challenging the evidence that AML derives exclusively from cellintrinsic defects. New studies have demonstrated that primary alterations of stromal cells, including MSCs, are able (e.g., by promoting an inflammatory or genotoxic microenvironment triggering alterations in HSCs) to induce the disease in mice models and in some cases in patients. Moreover, AML cells exploit MSC-dependent pro-survival signals and shape the 
BM microenvironment, in order to create a permissive/selfreinforcing niche favorable to escape therapy and immune response. All these concepts converge to indicate a fundamental bi-directional interaction between malignant cells and the BM microenvironment both contributing to AML onset and progression. Although the mechanisms underlying this crosstalk are just starting to be unraveled, an increasing body of evidence indicates that, similarly to other malignancies, targeting the AML microenvironment may be helpful at therapeutical level, thus being complementary to conventional treatments. This approach may lead to improved clinical results, especially for those patients, i.e., high-risk AML sufferers, who still have a dismal prognosis and whose management represents an unmet medical need. In this clinical scenario, a better understanding of cell-extrinsic and microenvironmental mechanisms underlying drug resistance constitutes a fundamental step for the design and development of new and potentially more effective therapies.

\section{AUTHOR CONTRIBUTIONS}

MCi wrote and revised the manuscript, and was the major contributor. GC wrote and revised sections of the manuscript.

\section{REFERENCES}

1. Tavassoli M, Crosby WH. Transplantation of marrow to extramedullary sites. Science. (1968) 161:54-6. doi: 10.1126/science.161.3836.54

2. Friedenstein AJ, Petrakova KV, Kurolesova AI, Frolova GP. Heterotopic of bone marrow. Analysis of precursor cells for osteogenic and hematopoietic tissues. Transplantation. (1968) 6:230-47. doi: 10.1097/00007890-196803000-00009

3. Friedenstein AJ, Chailakhjan RK, Lalykina KS. The development of fibroblast colonies in monolayer cultures of guinea-pig bone marrow and spleen cells. Cell Tissue Kinet. (1970) 3:393-403. doi: 10.1111/j.1365-2184.1970.tb00347.x

4. Friedenstein AJ, Chailakhyan RK, Latsinik NV, Panasyuk AF, Keiliss-Borok IV. Stromal cells responsible for transferring the microenvironment of the hemopoietic tissues. Cloning in vitro and retransplantation in vivo. Transplantation. (1974) 17:331-40. doi: 10.1097/00007890-197404000-00001

5. Dexter TM, Allen TD, Lajtha LG. Conditions controlling the proliferation of haemopoietic stem cells in vitro. J Cell Physiol. (1977) 91:335-44. doi: $10.1002 /$ jcp. 1040910303

6. Schofield R. The relationship between the spleen colony-forming cell and the haemopoietic stem cell. Blood Cells. (1978) 4:7-25.

7. Caplan AI. Mesenchymal stem cells. J Orthop Res. (1991) 9:641-50. doi: 10.1002/jor.1100090504

8. Bianco P, Robey PG, Simmons PJ. Mesenchymal stem cells: revisiting history, concepts, and assays. Cell Stem Cell. (2008) 2:313-9. doi: 10.1016/j.stem.2008.03.002

9. Morrison SJ, Scadden DT. The bone marrow niche for haematopoietic stem cells. Nature. (2014) 505:327-34. doi: 10.1038/nature12984

10. Anthony BA, Link DC. Regulation of hematopoietic stem cells by bone marrow stromal cells. Trends Immunol. (2014) 35:32-7. doi: 10.1016/j.it.2013.10.002

11. Uccelli A, Moretta L, Pistoia V. Mesenchymal stem cells in health and disease. Nat Rev Immunol. (2008) 8:726-36. doi: 10.1038/nri2395

12. Muguruma $Y$, Yahata $T$, Miyatake $H$, Sato $T$, Uno $T$, Itoh $J$, et al. Reconstitution of the functional human hematopoietic microenvironment derived from human mesenchymal stem cells in the murine bone marrow compartment. Blood. (2006) 107:1878-87. doi: 10.1182/blood-2005-06-2211
FL and FM collected the related papers. GV, AC, and $\mathrm{MCa}$ participated in the design of the review and helped to draft and revise the manuscript. AI wrote sections of the manuscript, participated in the design of the review, and helped to draft and revise the manuscript. All authors read and approved the final manuscript.

\section{FUNDING}

This work was supported by the FATRO/Foundation Corrado and Bruno Maria Zaini-Bologna, Fabbri1905, Bologna AIL (Associazione Italiana contro le Leucemie)/Section of Bologna and AIL Pesaro Onlus. MCi was supported by the University of Bologna (Alma Idea Junior Grant 2017), and the American Society of Hematology (ASH)/Giuseppe Bigi Memorial Award.

\section{ACKNOWLEDGMENTS}

We would like to thank Marie-Paule Vedrine and Bologna AIL (Associazione Italiana contro le Leucemie)/Section of Bologna for their kind support.

13. Devine SM, Bartholomew AM, Mahmud N, Nelson M, Patil S, Hardy W, et al. Mesenchymal stem cells are capable of homing to the bone marrow of non-human primates following systemic infusion. Exp Hematol. (2001) 29:244-55. doi: 10.1016/S0301-472X(00)00635-4

14. Bensidhoum, M., Chapel, A., Francois, S., Demarquay, C., Mazurier, C., Fouillard, L., et al. Homing of in vitro expanded Stro-1- or Stro-1+ human mesenchymal stem cells into the NOD/SCID mouse and their role in supporting human CD34 cell engraftment. Blood. (2004) 103:3313-9. doi: 10.1182/blood-2003-04-1121

15. Almeida-Porada G, Porada CD, Tran N, Zanjani ED. Cotransplantation of human stromal cell progenitors into preimmune fetal sheep results in early appearance of human donor cells in circulation and boosts cell levels in bone marrow at later time points after transplantation. Blood. (2000) 95:3620-7.

16. Dazzi F, Ramasamy R, Glennie S, Jones SP, Roberts I. The role of mesenchymal stem cells in haemopoiesis. Blood Rev. (2006) 20:161-71. doi: 10.1016/j.blre.2005.11.002

17. Saleh M, Shamsasanjan K, Movassaghpourakbari A, Akbarzadehlaleh P, Molaeipour Z. The impact of mesenchymal stem cells on differentiation of hematopoietic stem cells. Adv Pharm Bull. (2015) 5:299-304. doi: 10.15171/apb.2015.042

18. Wagner W, Roderburg C, Wein F, Diehlmann A, Frankhauser M, Schubert R, et al. Molecular and secretory profiles of human mesenchymal stromal cells and their abilities to maintain primitive hematopoietic progenitors. Stem Cells. (2007) 25:2638-47. doi: 10.1634/stemcells.2007-0280

19. Acar M, Kocherlakota KS, Murphy MM, Peyer JG, Oguro H, Inra CN, et al. Deep imaging of bone marrow shows non-dividing stem cells are mainly perisinusoidal. Nature. (2015) 526:126-30. doi: 10.1038/nature15250

20. Kiel MJ, Radice GL, Morrison SJ. Lack of evidence that hematopoietic stem cells depend on N-cadherin-mediated adhesion to osteoblasts for their maintenance. Cell Stem Cell. (2007) 1:204-17. doi: 10.1016/j.stem.2007.06.001

21. Lo Celso C, Fleming HE, Wu JW, Zhao CX, Miake-Lye S, Fujisaki J, et al. Live-animal tracking of individual haematopoietic stem/progenitor cells in their niche. Nature. (2009) 457:92-6. doi: 10.1038/nature 07434

22. Sugiyama T, Kohara H, Noda M, Nagasawa T. Maintenance of the hematopoietic stem cell pool by CXCL12-CXCR4 chemokine signaling 
in bone marrow stromal cell niches. Immunity. (2006) 25:977-88. doi: 10.1016/j.immuni.2006.10.016

23. Sacchetti B, Funari A, Michienzi S, Di Cesare S, Piersanti S, Saggio I, et al. Self-renewing osteoprogenitors in bone marrow sinusoids can organize a hematopoietic microenvironment. Cell. (2007) 131:324-36. doi: 10.1016/j.cell.2007.08.025

24. Mendez-Ferrer S, Michurina TV, Ferraro F, Mazloom AR, Macarthur BD, Lira SA, et al. Mesenchymal and haematopoietic stem cells form a unique bone marrow niche. Nature. (2010) 466:829-34. doi: 10.1038/nature09262

25. Ehninger A, Trumpp A. The bone marrow stem cell niche grows up: mesenchymal stem cells and macrophages move in. J Exp Med. (2011) 208:421-8. doi: 10.1084/jem.20110132

26. Quirici N, Soligo D, Bossolasco P, Servida F, Lumini C, Deliliers GL. Isolation of bone marrow mesenchymal stem cells by anti-nerve growth factor receptor antibodies. Exp Hematol. (2002) 30:783-91. doi: 10.1016/S0301-472X(02)00812-3

27. Tormin A, Li O, Brune JC, Walsh S, Schütz B, Ehinger M, et al. "CD146 expression on primary nonhematopoietic bone marrow stem cells is correlated with in situ localization. Blood. (2011) 117:5067-77. doi: 10.1182/blood-2010-08-304287

28. Chen S, Zambetti NA, Bindels EM, Kenswill K, Mylona AM, Adisty NM, et al. Massive parallel RNA sequencing of highly purified mesenchymal elements in low-risk MDS reveals tissue-context-dependent activation of inflammatory programs. Leukemia. (2016) 30:1938-42. doi: 10.1038/leu.2016.91

29. Matsuoka Y, Nakatsuka R, Sumide K, Kawamura H, Takahashi M, Fujioka T, et al. Prospectively isolated human bone marrow cell-derived MSCs support primitive human CD34-negative hematopoietic stem cells. Stem Cells. (2015) 33:1554-65. doi: 10.1002/stem.1941

30. Isern J, Martín-Antonio B, Ghazanfari R, Martín AM, López JA, del Toro R, et al. Self-renewing human bone marrow mesenspheres promote hematopoietic stem cell expansion. Cell Rep. (2013) 3:1714-24. doi: 10.1016/j.celrep.2013.03.041

31. Mabuchi Y, Morikawa S, Harada S, Niibe K, Suzuki S, Renault-Mihara F, et al. LNGFR(+)THY-1(+)VCAM-1(hi+) cells reveal functionally distinct subpopulations in mesenchymal stem cells. Stem Cell Rep. (2013) 1:152-65. doi: 10.1016/j.stemcr.2013.06.001

32. Le Blanc K, Tammik C, Rosendahl K, Zetterberg E, Ringdén O. HLA expression and immunologic properties of differentiated and undifferentiated mesenchymal stem cells. Exp Hematol. (2003) 31:890-6. doi: 10.1016/S0301-472X(03)00110-3

33. Machado, CeV, Telles PD, Nascimento IL. Immunological characteristics of mesenchymal stem cells. Rev Bras Hematol Hemoter. (2013) 35:62-7. doi: 10.5581/1516-8484.20130017

34. Aggarwal S, Pittenger MF. Human mesenchymal stem cells modulate allogeneic immune cell responses. Blood. (2005) 105:1815-22. doi: 10.1182/blood-2004-04-1559

35. Di Nicola M, Carlo-Stella C, Magni M, Milanesi M, Longoni PD, Matteucci P, et al. Human bone marrow stromal cells suppress T-lymphocyte proliferation induced by cellular or nonspecific mitogenic stimuli. Blood. (2002) 99:383843. doi: 10.1182/blood.V99.10.3838

36. Le Blanc K, Tammik L, Sundberg B, Haynesworth SE, Ringdén O. Mesenchymal stem cells inhibit and stimulate mixed lymphocyte cultures and mitogenic responses independently of the major histocompatibility complex. Scand J Immunol. (2003) 57:11-20. doi: 10.1046/j.1365-3083.2003.01176.x

37. Tse WT, Pendleton JD, Beyer WM, Egalka MC, Guinan EC. Suppression of allogeneic T-cell proliferation by human marrow stromal cells: implications in transplantation. Transplantation. (2003) 75:389-97. doi: 10.1097/01.TP.0000045055.63901.A9

38. Glennie S, Soeiro I, Dyson PJ, Lam EW, Dazzi F. Bone marrow mesenchymal stem cells induce division arrest anergy of activated $\mathrm{T}$ cells. Blood. (2005) 105:2821-7. doi: 10.1182/blood-200409-3696

39. Benvenuto F, Ferrari S, Gerdoni E, Gualandi F, Frassoni F, Pistoia V, et al. Human mesenchymal stem cells promote survival of $\mathrm{T}$ cells in a quiescent state. Stem Cells. (2007) 25:1753-60. doi: 10.1634/stemcells.2007-0068
40. Krampera M, Glennie S, Dyson J, Scott D, Laylor R, Simpson E, et al. Bone marrow mesenchymal stem cells inhibit the response of naive and memory antigen-specific T cells to their cognate peptide. Blood. (2003) 101:3722-9. doi: 10.1182/blood-2002-07-2104

41. Pevsner-Fischer M, Morad V, Cohen-Sfady M, Rousso-Noori L, ZaninZhorov A, Cohen S, et al. Toll-like receptors and their ligands control mesenchymal stem cell functions. Blood. (2007) 109:1422-32. doi: 10.1182/blood-2006-06-028704

42. Liotta F, Angeli R, Cosmi L, Filì L, Manuelli C, Frosali F, et al. Toll-like receptors 3 and 4 are expressed by human bone marrowderived mesenchymal stem cells and can inhibit their T-cell modulatory activity by impairing Notch signaling. Stem Cells. (2008) 26:279-89. doi: 10.1634/stemcells.2007-0454

43. Waterman RS, Tomchuck SL, Henkle SL, Betancourt AM. A new mesenchymal stem cell (MSC) paradigm: polarization into a proinflammatory MSC1 or an Immunosuppressive MSC2 phenotype. PLoS ONE. (2010) 5:e10088. doi: 10.1371/journal.pone.0010088

44. Zappia E, Casazza S, Pedemonte E, Benvenuto F, Bonanni I, Gerdoni $\mathrm{E}$, et al. Mesenchymal stem cells ameliorate experimental autoimmune encephalomyelitis inducing T-cell anergy. Blood. (2005) 106:1755-61. doi: 10.1182/blood-2005-04-1496

45. Krampera M, Cosmi L, Angeli R, Pasini A, Liotta F, Andreini A, et al. Role for interferon-gamma in the immunomodulatory activity of human bone marrow mesenchymal stem cells. Stem Cells. (2006) 24:386-98. doi: 10.1634/stemcells.2005-0008

46. DelaRosa O, Lombardo E, Beraza A, Mancheno-Corvo P, Ramirez C, Menta R, et al. "Requirement of IFN-gamma-mediated indoleamine 2,3dioxygenase expression in the modulation of lymphocyte proliferation by human adipose-derived stem cells." Tissue Eng A. (2009) 15:2795-806. doi: 10.1089/ten.tea.2008.0630

47. Rasmusson I, Ringdén O, Sundberg B, Le Blanc K. Mesenchymal stem cells inhibit the formation of cytotoxic T lymphocytes, but not activated cytotoxic T lymphocytes or natural killer cells. Transplantation. (2003) 76:1208-13. doi: 10.1097/01.TP.0000082540.43730.80

48. Yan Z, Zhuansun Y, Chen R, Li J, Ran P. Immunomodulation of mesenchymal stromal cells on regulatory $\mathrm{T}$ cells and its possible mechanism. Exp Cell Res. (2014) 324:65-74. doi: 10.1016/j.yexcr.2014.03.013

49. Selmani Z, Naji A, Zidi I, Favier B, Gaiffe E, Obert L, et al. (2008). Human leukocyte antigen-G5 secretion by human mesenchymal stem cells is required to suppress $\mathrm{T}$ lymphocyte and natural killer function and to induce CD4+CD25highFOXP3+ regulatory T cells. Stem Cells. 26:212-22. doi: 10.1634/stemcells.2007-0554

50. English K, Ryan JM, Tobin L, Murphy MJ, Barry FP, Mahon BP. Cell contact, prostaglandin $\mathrm{E}(2)$ and transforming growth factor beta 1 play non-redundant roles in human mesenchymal stem cell induction of CD4+CD25(High) forkhead box P3+ regulatory T cells. Clin Exp Immunol. (2009) 156:149-60. doi: 10.1111/j.1365-2249.2009.03874.x

51. Nauta AJ, Kruisselbrink AB, Lurvink E, Willemze R, Fibbe WE. Mesenchymal stem cells inhibit generation and function of both CD34+derived and monocyte-derived dendritic cells. J Immunol. (2006) 177:20807. doi: 10.4049/jimmunol.177.4.2080

52. Zhang W, Ge W, Li C, You S, Liao L, Han Q, et al. Effects of mesenchymal stem cells on differentiation, maturation, and function of human monocyte-derived dendritic cells. Stem Cells Dev. (2004) 13:263-71. doi: 10.1089/154732804323099190

53. Jiang XX, Zhang Y, Liu B, Zhang SX, Wu Y, Yu XD, et al. Human mesenchymal stem cells inhibit differentiation and function of monocyte-derived dendritic cells. Blood. (2005) 105:4120-6. doi: 10.1182/blood-2004-02-0586

54. Djouad F, Charbonnier LM, Bouffi, C, Louis-Plence P, Bony C, Apparailly $\mathrm{F}$, et al. Mesenchymal stem cells inhibit the differentiation of dendritic cells through an interleukin-6-dependent mechanism. Stem Cells. (2007) 25:2025-32. doi: 10.1634/stemcells.2006-0548

55. Spaggiari GM, Abdelrazik H, Becchetti F, Moretta L. MSCs inhibit monocytederived DC maturation and function by selectively interfering with the generation of immature DCs: central role of MSC-derived prostaglandin E2. Blood. (2009) 113:6576-83. doi: 10.1182/blood-2009-02-203943 
56. Reis M, Mavin E, Nicholson L, Green K, Dickinson AM, Wang $\mathrm{XN}$. Mesenchymal stromal cell-derived extracellular vesicles attenuate dendritic cell maturation and function. Front Immunol. (2018) 9:2538. doi: $10.3389 /$ fimmu.2018.02538

57. Spaggiari GM, Capobianco A, Becchetti S, Mingari MC, Moretta L. Mesenchymal stem cell-natural killer cell interactions: evidence that activated NK cells are capable of killing MSCs, whereas MSCs can inhibit IL-2-induced NK-cell proliferation. Blood. (2006) 107:1484-90. doi: 10.1182/blood-2005-07-2775

58. Gao S, Mao F, Zhang B, Zhang L, Zhang X, Wang M, et al. Mouse bone marrow-derived mesenchymal stem cells induce macrophage M2 polarization through the nuclear factor-kappaB and signal transducer and activator of transcription 3 pathways. Exp Biol Med. (2014) 239:366-75. doi: $10.1177 / 1535370213518169$

59. Vasandan AB, Jahnavi S, Shashank C, Prasad P, Kumar A, Prasanna SJ. Human Mesenchymal stem cells program macrophage plasticity by altering their metabolic status via a PGE. Sci Rep. (2016) 6:38308. doi: $10.1038 /$ srep38308

60. Gong L, Zhao Y, Zhang Y, Ruan Z. The macrophage polarization regulates MSC osteoblast differentiation in vitro. Ann Clin Lab Sci. (2016) 46:65-71.

61. Chen L, Tredget EE, Wu PY, Wu Y. Paracrine factors of mesenchymal stem cells recruit macrophages and endothelial lineage cells and enhance wound healing. PLoS ONE. (2008) 3:e1886. doi: 10.1371/journal.pone.0001886

62. Marigo I, Dazzi F. The immunomodulatory properties of mesenchymal stem cells. Semin Immunopathol. (2011) 33:593-602. doi: 10.1007/s00281-011-0267-7

63. Le Blanc K, Frassoni F, Ball L, Locatelli F, Roelofs H, Lewis I, et al. Mesenchymal stem cells for treatment of steroid-resistant, severe, acute graft-versus-host disease: a phase II study. Lancet. (2008) 371:1579-86. doi: 10.1016/S0140-6736(08)60690-X

64. von Dalowski F, Kramer M, Wermke M, Wehner R, Rollig C, Alakel N, et al. Mesenchymal stromal cells for treatment of acute steroid-refractory graft versus host disease: clinical responses and long-term outcome. Stem Cells. (2016) 34:357-66. doi: 10.1002/stem.2224

65. Galleu A, Milojkovic D, Deplano S, Szydlo R, Loaiza S, Wynn R, et al. Mesenchymal stromal cells for acute graft-versus-host disease: response at 1 week predicts probability of survival. Br J Haematol. (2019) 185:89-92. doi: 10.1111/bjh.15749

66. Resnick IB, Barkats C, Shapira MY, Stepensky P, Bloom AI, Shimoni A, et al. Treatment of severe steroid resistant acute GVHD with mesenchymal stromal cells (MSC). Am J Blood Res. (2013) 3:225-38.

67. Introna M, Lucchini G, Dander E, Galimberti S, Rovelli A, Balduzzi A, et al. Treatment of graft versus host disease with mesenchymal stromal cells: a phase I study on 40 adult and pediatric patients. Biol Blood Marrow Transplant. (2014) 20:375-81. doi: 10.1016/j.bbmt.2013.11.033

68. Sánchez-Guijo F, Caballero-Velázquez T, López-Villar O, Redondo A, Parody $\mathrm{R}$, Martínez C, et al. Sequential third-party mesenchymal stromal cell therapy for refractory acute graft-versus-host disease. Biol Blood Marrow Transplant. (2014) 20:1580-5. doi: 10.1016/j.bbmt.2014.06.015

69. Servais S, Baron F, Lechanteur C, Seidel L, Selleslag D, Maertens $\mathrm{J}$, et al. Infusion of bone marrow derived multipotent mesenchymal stromal cells for the treatment of steroid-refractory acute graft-versus-host disease: a multicenter prospective study. Oncotarget. (2018) 9:20590-604. doi: 10.18632/oncotarget.25020

70. Bader P, Kuçi Z, Bakhtiar S, Basu O, Bug G, Dennis M, et al. Effective treatment of steroid and therapy-refractory acute graft-versus-host disease with a novel mesenchymal stromal cell product (MSC-FFM). Bone Marrow Transplant. (2018) 53:852-62. doi: 10.1038/s41409-018-0102-z

71. Döhner H, Weisdorf DJ, Bloomfield CD. Acute myeloid leukemia. N Engl J Med. (2015) 373:1136-52. doi: 10.1056/NEJMra1406184

72. Mossner M, Jann JC, Wittig J, Nolte F, Fey S, Nowak V, et al. Mutational hierarchies in myelodysplastic syndromes dynamically adapt and evolve upon therapy response and failure. Blood. (2016) 128:1246-59. doi: 10.1182/blood-2015-11-679167

73. Raaijmakers MH, Mukherjee S, Guo S, Zhang S, Kobayashi T, Schoonmaker JA, et al. Bone progenitor dysfunction induces myelodysplasia and secondary leukaemia. Nature. (2010) 464:852-7. doi: 10.1038/nature 08851
74. Santamaría C, Muntión S, Rosón B, Blanco B, López-Villar O, Carrancio S, et al. Impaired expression of DICER, DROSHA, SBDS and some microRNAs in mesenchymal stromal cells from myelodysplastic syndrome patients. Haematologica. (2012) 97:1218-24. doi: 10.3324/haematol.2011.054437

75. Zambetti NA, Ping Z, Chen S, Kenswil KJG, Mylona MA, Sanders MA, et al. Mesenchymal Inflammation Drives Genotoxic Stress in Hematopoietic Stem Cells and Predicts Disease Evolution in Human Pre-leukemia. Cell Stem Cell. (2016) 19:613-27. doi: 10.1016/j.stem.2016.08.021

76. Kode A, Manavalan JS, Mosialou I, Bhagat G, Rathinam CV, Luo N, et al. Leukaemogenesis induced by an activating $\beta$-catenin mutation in osteoblasts. Nature. (2014) 506:240-4. doi: 10.1038/nature12883

77. Kode A, Mosialou I, Manavalan SJ, Rathinam CV, Friedman RA, TeruyaFeldstein J, et al. FoxO1-dependent induction of acute myeloid leukemia by osteoblasts in mice. Leukemia. (2016) 30:1-13. doi: 10.1038/leu.2015.161

78. Dong L, Yu WM, Zheng $\mathrm{H}$, Loh ML, Bunting ST, Pauly M, et al. Leukaemogenic effects of Ptpn11 activating mutations in the stem cell microenvironment. Nature. (2016) 539:304-8. doi: 10.1038/nature20131

79. Sala-Torra O, Hanna C, Loken MR, Flowers ME, Maris M, Ladne PA, et al. Evidence of donor-derived hematologic malignancies after hematopoietic stem cell transplantation. Biol Blood Marrow Transplant. (2006) 12:511-7. doi: 10.1016/j.bbmt.2006.01.006

80. Wiseman DH. Donor cell leukemia: a review. Biol Blood Marrow Transplant. (2011) 17:771-89. doi: 10.1016/j.bbmt.2010.10.010

81. Blau O, Hofmann WK, Baldus CD, Thiel G, Serbent V, Schümann E, et al. Chromosomal aberrations in bone marrow mesenchymal stroma cells from patients with myelodysplastic syndrome and acute myeloblastic leukemia. Exp Hematol. (2007) 35:221-9. doi: 10.1016/j.exphem.2006.10.012

82. Kouvidi E, Stratigi A, Batsali A, Mavroudi I, Mastrodemou S, Ximeri M, et al. Cytogenetic evaluation of mesenchymal stem/stromal cells from patients with myelodysplastic syndromes at different time-points during ex vivo expansion. Leuk Res. (2016) 43:24-32. doi: 10.1016/j.leukres.2016.02.007

83. Korn C, Méndez-Ferrer S. Myeloid malignancies and the microenvironment. Blood. (2017) 129:811-22. doi: 10.1182/blood-2016-09-670224

84. Flores-Figueroa E, Arana-Trejo RM, Gutiérrez-Espíndola G, Pérez-Cabrera A, Mayani H. Mesenchymal stem cells in myelodysplastic syndromes: phenotypic and cytogenetic characterization. Leuk Res. (2005) 29:215-24. doi: 10.1016/j.leukres.2004.06.011

85. Flores-Figueroa E, Montesinos JJ, Flores-Guzmán P, Gutiérrez-Espíndola G, Arana-Trejo RM, Castillo-Medina S, et al. Functional analysis of myelodysplastic syndromes-derived mesenchymal stem cells. Leuk Res. (2008) 32:1407-16. doi: 10.1016/j.leukres.2008.02.013

86. Corradi G, Baldazzi C, Očadlíková D, Marconi G, Parisi S, Testoni N, et al. Mesenchymal stromal cells from myelodysplastic and acute myeloid leukemia patients display in vitro reduced proliferative potential and similar capacity to support leukemia cell survival. Stem Cell Res Ther. (2018) 9:271. doi: 10.1186/s13287-018-1013-z

87. Geyh S, Rodríguez-Paredes M, Jäger P, Khandanpour C, Cadeddu RP, Gutekunst J, et al. Functional inhibition of mesenchymal stromal cells in acute myeloid leukemia. Leukemia. (2016) 30:683-91. doi: 10.1038/leu.2015.325

88. Sorokina T, Shipounova I, Bigildeev A, Petinati N, Drize N, Turkina A, et al. The ability of multipotent mesenchymal stromal cells from the bone marrow of patients with leukemia to maintain normal hematopoietic progenitor cells. Eur J Haematol. (2016) 97:245-52. doi: 10.1111/ejh.12713

89. Aanei CM, Flandrin P, Eloae FZ, Carasevici E, Guyotat D, Wattel $\mathrm{E}$, et al. Intrinsic growth deficiencies of mesenchymal stromal cells in myelodysplastic syndromes. Stem Cells Dev. (2012) 21:1604-15. doi: $10.1089 /$ scd.2011.0390

90. Geyh S, Oz S, Cadeddu RP, Fröbel J, Brückner B, Kündgen A, et al. Insufficient stromal support in MDS results from molecular and functional deficits of mesenchymal stromal cells. Leukemia. (2013) 27:1841-51. doi: 10.1038/leu.2013.193

91. Kim JA, Shim JS, Lee GY, Yim HW, Kim TM, Kim M, et al. Microenvironmental remodeling as a parameter and prognostic factor of heterogeneous leukemogenesis in acute myelogenous leukemia. Cancer Res. (2015) 75:2222-31. doi: 10.1158/0008-5472.CAN-14-3379

92. Vicente Lopez A, Vazquez Garcia MN, Melen GJ, Entrena Martinez A, Cubillo Moreno I, Garcia-Castro J, et al. Mesenchymal stromal cells derived 
from the bone marrow of acute lymphoblastic leukemia patients show altered BMP4 production: correlations with the course of disease. PLoS ONE. (2014) 9:e84496. doi: 10.1371/journal.pone.0084496

93. Diaz de la Guardia R, Lopez-Millan B, Lavoie JR, Bueno C, Castaño J, Gómez-Casares M, et al. Detailed characterization of mesenchymal stem/stromal cells from a large cohort of AML patients demonstrates a definitive link to treatment outcomes. Stem Cell Rep. (2017) 8:1573-86). doi: 10.1016/j.stemcr.2017.04.019

94. Medyouf H, Mossner M, Jann JC, Nolte F, Raffel S, Herrmann C, et al. Myelodysplastic cells in patients reprogram mesenchymal stromal cells to establish a transplantable stem cell niche disease unit. Cell Stem Cell. (2014) 14:824-37. doi: 10.1016/j.stem.2014.02.014

95. Duarte D, Hawkins ED, Lo Celso C. The interplay of leukemia cells and the bone marrow microenvironment. Blood. (2018) 131:1507-11. doi: 10.1182/blood-2017-12-784132

96. Frisch BJ, Ashton JM, Xing L, Becker MW, Jordan CT, Calvi LM. Functional inhibition of osteoblastic cells in an in vivo mouse model of myeloid leukemia. Blood. (2012) 119:540-50. doi: 10.1182/blood-2011-04-348151

97. Raposo G, Stoorvogel W. Extracellular vesicles: exosomes, microvesicles, and friends. J Cell Biol. (2013) 200:373-83. doi: 10.1083/jcb.201211138

98. van Niel G, D'Angelo G, Raposo G. Shedding light on the cell biology of extracellular vesicles. Nat Rev Mol Cell Biol. (2018) 19:213-28. doi: $10.1038 / \mathrm{nrm} .2017 .125$

99. Kumar B, Garcia M, Murakami JL, Chen CC. Exosome-mediated microenvironment dysregulation in leukemia. Biochim Biophys Acta. (2016) 1863:464-70. doi: 10.1016/j.bbamcr.2015.09.017

100. Ohyashiki JH, Umezu T, Ohyashiki K. Exosomes promote bone marrow angiogenesis in hematologic neoplasia: the role of hypoxia. Curr Opin Hematol. (2016) 23:268-73. doi: 10.1097/MOH.0000000000000235

101. Hong CS, Muller L, Boyiadzis M, Whiteside TL. Isolation and characterization of $\mathrm{CD} 34+$ blast-derived exosomes in acute myeloid leukemia. PLoS ONE. (2014) 9:e103310. doi: 10.1371/journal.pone.0103310

102. Boyiadzis $M$, Whiteside TL. The emerging roles of tumor-derived exosomes in hematological malignancies. Leukemia. (2017) 31:1259-68. doi: 10.1038/leu.2017.91

103. Kumar B, Garcia M, Weng L, Jung X, Murakami JL, Hu X, et al. Acute myeloid leukemia transforms the bone marrow niche into a leukemiapermissive microenvironment through exosome secretion. Leukemia. (2018) 32:575-87. doi: 10.1038/leu.2017.259

104. Li X, Miao H, Zhang Y, Li W, Li Z, Zhou Y, et al. (2015). Bone marrow microenvironment confers imatinib resistance to chronic myelogenous leukemia and oroxylin A reverses the resistance by suppressing Stat3 pathway. Arch Toxicol. (2015) 89:121-36. doi: 10.1007/s00204-014-1226-6

105. Boyerinas B, Zafrir M, Yesilkanal AE, Price TT, Hyjek EM, Sipkins DA. Adhesion to osteopontin in the bone marrow niche regulates lymphoblastic leukemia cell dormancy. Blood. (2013) 121:4821-31. doi: 10.1182/blood-2012-12-475483

106. Shishido S, Bonig H, Kim YM. Role of integrin alpha4 in drug resistance of leukemia. Front Oncol. (2014) 4:99. doi: 10.3389/fonc.2014.00099

107. Matsunaga T, Takemoto N, Sato T, Takimoto R, Tanaka I, Fujimi A, et al. Interaction between leukemic-cell VLA-4 and stromal fibronectin is a decisive factor for minimal residual disease of acute myelogenous leukemia. Nat Med. (2003) 9:1158-65. doi: 10.1038/nm909

108. Meads MB, Hazlehurst LA, Dalton WS. The bone marrow microenvironment as a tumor sanctuary and contributor to drug resistance. Clin Cancer Res. (2008) 14:2519-26. doi: 10.1158/1078-0432.CCR-07-2223

109. Benabbou N, Mirshahi P, Bordu C, Faussat AM, Tang R, Therwath A, et al. A subset of bone marrow stromal cells regulate ATP-binding cassette gene expression via insulin-like growth factor-I in a leukemia cell line. Int J Oncol. (2014) 45:1372-80. doi: 10.3892/ijo.2014.2569

110. Correia AL, Bissell MJ. The tumor microenvironment is a dominant force in multidrug resistance. Drug Resist Updat. (2012) 15:39-49. doi: 10.1016/j.drup.2012.01.006

111. Campos L, Rouault JP, Sabido O, Oriol P, Roubi N, Vasselon C, et al. High expression of bcl-2 protein in acute myeloid leukemia cells is associated with poor response to chemotherapy. Blood. (1993)81:3091-6.

112. Norgaard JM, Langkjer ST, Palshof T, Clausen N, Pedersen B, Hokland P. Relation of blast cell survival and proliferation to chemotherapy resistance in AML. Br J Haematol. (1996) 93:888-97. doi: 10.1046/j.1365-2141.1996.d01-1735.x

113. Banker DE, Groudine M, Norwood T, Appelbaum FR. Measurement of spontaneous and therapeutic agent-induced apoptosis with BCL-2 protein expression in acute myeloid leukemia. Blood. (1997) 89:243-55.

114. Maung ZT, Hogarth L, Reid MM, Proctor SJ, Hamilton PJ, Hall AG. Raised intracellular glutathione levels correlate with in vitro resistance to cytotoxic drugs in leukaemic cells from patients with acute lymphoblastic leukemia. Leukemia. (1994) 8:1487-91.

115. Porwit-MacDonald A, Ivory K, Wilkinson S, Wheatley K, Wong L, Janossy G. Bcl-2 protein expression in normal human bone marrow precursors and in acute myelogenous leukemia. Leukemia. (1995) 9:1191-8.

116. Garrido SM, Appelbaum FR, Willman CL, Banker DE. Acute myeloid leukemia cells are protected from spontaneous and drug-induced apoptosis by direct contact with a human bone marrow stromal cell line (HS-5). Exp Hematol. (2001) 29:448-57. doi: 10.1016/S0301-472X(01)00612-9

117. Bendall LJ, Daniel A, Kortlepel K, Gottlieb DJ. Bone marrow adherent layers inhibit apoptosis of acute myeloid leukemia cells. Exp Hematol. (1994) 22:1252-60.

118. Konopleva M, Konoplev S, Hu W, Zaritskey AY, Afanasiev BV, Andreeff M. Stromal cells prevent apoptosis of AML cells by upregulation of anti-apoptotic proteins. Leukemia. (2002) 16:1713-24. doi: 10.1038/sj.leu.2402608

119. Wei Z, Chen N, Guo H, Wang X, Xu F, Ren Q, et al. Bone marrow mesenchymal stem cells from leukemia patients inhibit growth and apoptosis in serum-deprived K562 cells. J Exp Clin Cancer Res. (2009) 28:141. doi: 10.1186/1756-9966-28-141

120. Tabe Y, Jin L, Tsutsumi-Ishii Y, Xu Y, McQueen T, Priebe WB, et al. Activation of integrin-linked kinase is a critical prosurvival pathway induced in leukemic cells by bone marrow-derived stromal cells. Cancer Res. (2007) 67:684-94. doi: 10.1158/0008-5472.CAN-06-3166

121. Golay J, Cuppini L, Leoni F, Mico C, Barbui V, Domenghini M, et al. The histone deacetylase inhibitor ITF2357 has anti-leukemic activity in vitro and in vivo and inhibits IL-6 and VEGF production by stromal cells. Leukemia. (2007) 21:1892-900. doi: 10.1038/sj.leu.2404860

122. Menzel T, Rahman Z, Calleja E, White K, Wilson EL, Wieder R, et al. Elevated intracellular level of basic fibroblast growth factor correlates with stage of chronic lymphocytic leukemia and is associated with resistance to fludarabine. Blood. (1996) 87:1056-63. doi: 10.1182/blood.V87.3.1056.bloodjournal8731056

123. Kampen KR, Ter Elst A, de Bont ES. Vascular endothelial growth factor signaling in acute myeloid leukemia. Cell Mol Life Sci. (2013) 70:1307-17. doi: 10.1007/s00018-012-1085-3

124. Burger JA, Tsukada N, Burger M, Zvaifler NJ, Dell'Aquila M, Kipps TJ. Blood-derived nurse-like cells protect chronic lymphocytic leukemia B cells from spontaneous apoptosis through stromal cell-derived factor-1. Blood. (2000) 96:2655-63.

125. Burger JA, Kipps TJ. CXCR4: a key receptor in the crosstalk between tumor cells and their microenvironment. Blood. (2006) 107:1761-7. doi: 10.1182/blood-2005-08-3182

126. Zeng Z, Samudio IJ, Munsell M, An J, Huang Z, Estey E, et al. Inhibition of CXCR4 with the novel RCP168 peptide overcomes stroma-mediated chemoresistance in chronic and acute leukemias. Mol Cancer Ther. (2006) 5:3113-21. doi: 10.1158/1535-7163.MCT-06-0228

127. Burger JA, Burkle A. The CXCR4 chemokine receptor in acute and chronic leukaemia: a marrow homing receptor and potential therapeutic target. $\mathrm{Br} J$ Haematol. (2007) 137:288-96. doi: 10.1111/j.1365-2141.2007.06590.x

128. Tavor S, Petit I, Porozov S, Avigdor A, Dar A, Leider-Trejo L, et al. CXCR4 regulates migration and development of human acute myelogenous leukemia stem cells in transplanted NOD/SCID mice. Cancer Res. (2004) 64:2817-24. doi: 10.1158/0008-5472.CAN-03-3693

129. Yanamandra N, Colaco NM, Parquet NA, Buzzeo RW, Boulware $D$, Wright G, et al. Tipifarnib and bortezomib are synergistic and overcome cell adhesion-mediated drug resistance in multiple myeloma and acute myeloid leukemia. Clin Cancer Res. (2006) 12:591-9. doi: 10.1158/1078-0432.CCR-05-1792

130. Patel V, Chen LS, Wierda WG, Balakrishnan K, Gandhi V. Impact of bone marrow stromal cells on Bcl-2 family members 
in chronic lymphocytic leukemia. Leuk Lymp. (2014) 55:899-910. doi: 10.3109/10428194.2013.819573

131. Pan R, Hogdal LJ, Benito JM, Bucci D, Han L, Borthakur G, et al. Selective BCL-2 inhibition by ABT-199 causes on-target cell death in acute myeloid leukemia. Cancer Discov. (2014) 4:362-75. doi: 10.1158/2159-8290.CD-13-0609

132. Karjalainen R, Pemovska T, Popa M, Liu M, Javarappa KK, Majumder $\mathrm{MM}$, et al. JAK1/2 and BCL2 inhibitors synergize to counteract bone marrow stromal cell-induced protection of AML. Blood. (2017) 130:789-802. doi: 10.1182/blood-2016-02-699363

133. Jin L, Hope KJ, Zhai Q, Smadja-Joffe F, Dick JE. Targeting of CD44 eradicates human acute myeloid leukemic stem cells. Nat Med. (2006) 12:1167-74. doi: $10.1038 / \mathrm{nm} 1483$

134. Isidori A, Loscocco F, Curti A, Amadori S, Visani G. Genomic profiling and predicting treatment response in acute myeloid leukemia. Pharmacogenomics. (2019) 20:467-70. doi: 10.2217/pgs-2018-0202

135. Borger V, Bremer M, Ferrer-Tur R, Gockeln L, Stambouli O, Becic A, Giebel B. Mesenchymal stem/stromal cell-derived extracellular vesicles and their potential as novel immunomodulatory therapeutic agents. Int J Mol Sci. (2017) 18:E1450. doi: 10.3390/ijms18071450

136. Kordelas L, Rebmann V, Ludwig AK, Radtke S, Ruesing J, Doeppner TR, et al. MSC-derived exosomes: a novel tool to treat therapy-refractory graft-versushost disease. Leukemia. (2014) 28:970-3. doi: 10.1038/leu.2014.41

137. Zhou J, Tan X, Tan Y, Li Q, Ma J, Wang G. Mesenchymal stem cell derived exosomes in cancer progression, metastasis and drug delivery: a comprehensive review. J Cancer. (2018) 9:3129-37. doi: 10.7150/jca.25376

138. Lopatina T, Gai C, Deregibus MC, Kholia S, Camussi G. Cross talk between cancer and mesenchymal stem cells through extracellular vesicles carrying nucleic acids. Front Oncol. (2016) 6:125. doi: 10.3389/fonc.2016.00125

139. Adamo A, Dal Collo G, Bazzoni R, Krampera M. Role of mesenchymal stromal cell-derived extracellular vesicles in tumour microenvironment. Biochim Biophys Acta Rev Cancer. (2019) 1871:192-8. doi: 10.1016/j.bbcan.2018.12.001

140. Lee JK, Park SR, Jung BK, Jeon YK, Lee YS, Kim MK, et al. Exosomes derived from mesenchymal stem cells suppress angiogenesis by downregulating VEGF expression in breast cancer cells. PLoS ONE. (2013) 8:e84256. doi: 10.1371/journal.pone.0084256

141. Katakowski M, Buller B, Zheng X, Lu Y, Rogers T, Osobamiro O, et al. Exosomes from marrow stromal cells expressing miR-146b inhibit glioma growth. Cancer Lett. (2013) 335:201-4. doi: 10.1016/j.canlet.2013.02.019

142. Bruno S, Collino F, Deregibus MC, Grange C, Tetta C, Camussi G. Microvesicles derived from human bone marrow mesenchymal stem cells inhibit tumor growth. Stem Cells Dev. (2013) 22:758-71. doi: $10.1089 / \mathrm{scd} .2012 .0304$

143. Barrera-Ramirez J, Lavoie JR, Maganti HB, Stanford WL, Ito C, Sabloff M, et al. mMicro-RNA profiling of exosomes from marrowderived mesenchymal stromal cells in patients with acute myeloid leukemia: implications in leukemogenesis. Stem Cell Rev. (2017) 13:817-25. doi: 10.1007/s12015-017-9762-0

144. Chauveau A, Aucher A, Eissmann P, Vivier E, Davis DM. Membrane nanotubes facilitate long-distance interactions between natural killer cells and target cells. Proc Natl Acad Sci USA. (2010) 107:5545-50. doi: $10.1073 /$ pnas. 0910074107

145. Onfelt B, Nedvetzki S, Yanagi K, Davis DM. Cutting edge: Membrane nanotubes connect immune cells. J Immunol. (2004) 173:1511-3. doi: 10.4049/jimmunol.173.3.1511

146. Rustom A, Saffrich R, Markovic I, Walther P, Gerdes HH. Nanotubular highways for intercellular organelle transport. Science. (2004) 303:1007-10. doi: $10.1126 /$ science. 1093133

147. Watkins SC, Salter RD. Functional connectivity between immune cells mediated by tunneling nanotubules. Immunity. (2005) 23:309-18. doi: 10.1016/j.immuni.2005.08.009

148. Omsland M, Bruserud O, Gjertsen BT, Andresen V. Tunneling nanotube (TNT) formation is downregulated by cytarabine and NF-kappaB inhibition in acute myeloid leukemia (AML). Oncotarget. (2017) 8:7946-63. doi: 10.18632/oncotarget.13853

149. Pasquier J, Guerrouahen BS, Al Thawadi H, Ghiabi P, Maleki M, Abu-Kaoud $\mathrm{N}$, et al. Preferential transfer of mitochondria from endothelial to cancer cells through tunneling nanotubes modulates chemoresistance. J Transl Med. (2013) 11:94. doi: 10.1186/1479-5876-11-94

150. Marlein CR, Zaitseva L, Piddock RE Robinson SD, Edwards DR, Shafat MS, et al. NADPH oxidase-2 derived superoxide drives mitochondrial transfer from bone marrow stromal cells to leukemic blasts. Blood. (2017) 130:164960. doi: 10.1182/blood-2017-03-772939

151. Samudio I, Harmancey R, Fiegl M, Kantarjian H, Konopleva M, Korchin $B$, et al. Pharmacologic inhibition of fatty acid oxidation sensitizes human leukemia cells to apoptosis induction. J Clin Invest. (2010) 120:142-56. doi: 10.1172/JCI38942

152. Lagadinou ED, Sach A, Callahan K, Rossi RM, Neering SJ, Minhajuddin $\mathrm{M}$, et al. BCL-2 inhibition targets oxidative phosphorylation and selectively eradicates quiescent human leukemia stem cells. Cell Stem Cell. (2013) 12:329-41. doi: 10.1016/j.stem.2012.12.013

153. Samudio I, Fiegl M, McQueen T, Clise-Dwyer K, Andreeff M. The warburg effect in leukemia-stroma cocultures is mediated by mitochondrial uncoupling associated with uncoupling protein 2 activation. Cancer Res. (2008) 68:5198-205. doi: 10.1158/0008-5472.CAN-08-0555

154. Samudio I, Fiegl M, Andreeff M. Mitochondrial uncoupling and the Warburg effect: molecular basis for the reprogramming of cancer cell metabolism. Cancer Res. (2009) 69:2163-6. doi: 10.1158/0008-5472.CAN-08-3722

155. Suganuma K, Miwa H, Imai N, Shikami M, Gotou M, Goto M, et al. Energy metabolism of leukemia cells: glycolysis versus oxidative phosphorylation. Leuk Lymp. (2010) 51:2112-9. doi: 10.3109/10428194.2010.512966

156. Boultwood J, Fidler C, Mills KI, Frodsham PM, Kusec R, Gaiger AA, et al. Amplification of mitochondrial DNA in acute myeloid leukaemia. $\mathrm{Br} \mathrm{J}$ Haematol. (1996) 95:426-31. doi: 10.1046/j.1365-2141.1996.d01-1922.x

157. Skrtic M, Sriskanthadevan S, Jhas B, Gebbia M, Wang X, Wang Z, et al. Inhibition of mitochondrial translation as a therapeutic strategy for human acute myeloid leukemia. Cancer Cell. (2011) 20:674-88. doi: 10.1016/j.ccr.2011.10.015

158. Moschoi R, Imbert V, Nebout M, Chiche J, Mary D, Prebet T, et al. Protective mitochondrial transfer from bone marrow stromal cells to acute myeloid leukemic cells during chemotherapy. Blood. (2016) 128:253-64. doi: 10.1182/blood-2015-07-655860

159. Marlein CR, Zaitseva L, Piddock RE, Raso-Barnett L, Scott MA, Ingham CJ, et al. PGC-1alpha driven mitochondrial biogenesis in stromal cells underpins mitochondrial trafficking to leukemic blasts. Leukemia. (2018) 32:2073-7. doi: 10.1038/s41375-018-0221-y

160. Leverson JD, Cojocari D. Hematologic tumor cell resistance to the BCL-2 inhibitor venetoclax: a product of its microenvironment? Front Oncol. (2018) 8:458. doi: 10.3389/fonc.2018.00458

161. Pollyea DA, Kohrt HE, Gallegos L, Figueroa ME, Abdel-Wahab O, Zhang BS, et al. Safety, efficacy and biological predictors of response to sequential azacitidine and lenalidomide for elderly patients with acute myeloid leukemia. Leukemia. (2012) 26:893-901. doi: 10.1038/leu.2011.294

162. Wise DR, Thompson CB. Glutamine addiction: a new therapeutic target in cancer. Trends Biochem Sci. (2010) 35:427-33. doi: 10.1016/j.tibs.2010.05.003

163. Matre P, Velez J, Jacamo R, Qi Y, Su X, Cai T, et al. Inhibiting glutaminase in acute myeloid leukemia: metabolic dependency of selected AML subtypes. Oncotarget. (2016) 7:79722-35. doi: 10.18632/oncotarget.12944

164. Ohkouchi S, Block GJ, Katsha AM, Kanehira M, Ebina M, Kikuchi T, et al. Mesenchymal stromal cells protect cancer cells from ROS-induced apoptosis and enhance the Warburg effect by secreting STC1. Mol Ther. (2012) 20:417-23. doi: 10.1038/mt.2011.259

165. Benito J, Shi Y, Szymanska B, Carol H, Boehm I, Lu H, et al. Pronounced hypoxia in models of murine and human leukemia: high efficacy of hypoxia-activated prodrug PR-104. PLoS ONE. (2011) 6:e23108. doi: 10.1371/journal.pone.0023108

166. Staller P, Sulitkova J, Lisztwan J, Moch H, Oakeley EJ, Krek W. Chemokine receptor CXCR4 downregulated by von Hippel-Lindau tumour suppressor pVHL. Nature. (2003) 425:307-11. doi: 10.1038/nature01874

167. Vander Heiden MG, Plas DR, Rathmell JC, Fox CJ, Harris MH, Thompson CB. Growth factors can influence cell growth and survival through effects on glucose metabolism. Mol Cell Biol. (2001) 21:5899-912. doi: 10.1128/MCB.21.17.5899-5912.2001

168. Frolova O, Samudio I, Benito JM, Jacamo R, Kornblau SM, Markovic $\mathrm{A}$, et al. Regulation of HIF-1alpha signaling and chemoresistance in 
acute lymphocytic leukemia under hypoxic conditions of the bone marrow microenvironment. Cancer Biol Ther. (2012) 13:858-70. doi: $10.4161 /$ cbt. 20838

169. Turley SJ, Cremasco V, Astarita JL. Immunological hallmarks of stromal cells in the tumour microenvironment. Nat Rev Immunol. (2015) 15:669-82. doi: $10.1038 /$ nri3902

170. Curti A, Trabanelli S, Salvestrini V, Baccarani M, Lemoli RM. The role of indoleamine 2,3-dioxygenase in the induction of immune tolerance: focus on hematology. Blood. (2009) 113:2394-401. doi: 10.1182/blood-2008-07-144485

171. Mellor AL, Munn DH. IDO expression by dendritic cells: tolerance and tryptophan catabolism. Nat Rev Immunol. (2004) 4:762-74. doi: $10.1038 /$ nri1457

172. Prendergast GC, Smith C, Thomas S, Mandik-Nayak L, Laury-Kleintop L, Metz R, Muller AJ. Indoleamine 2,3-dioxygenase pathways of pathogenic inflammation and immune escape in cancer. Cancer Immunol Immunother. (2014) 63:721-35. doi: 10.1007/s00262-014-1549-4

173. Beyer M, Schultze JL. Regulatory T cells in cancer. Blood. (2006) 108:804-11. doi: 10.1182/blood-2006-02-002774

174. Teague RM, Kline J. Immune evasion in acute myeloid leukemia: current concepts and future directions. J Immunother Cancer. (2013) 1:1. doi: 10.1186/2051-1426-1-13

175. Curti A, Aluigi M, Pandolfi S, Ferri E, Isidori A, Salvestrini V, et al. Acute myeloid leukemia cells constitutively express the immunoregulatory enzyme indoleamine 2,3-dioxygenase. Leukemia. (2007) 21:353-5. doi: 10.1038/sj.leu.2404485

176. Curti A, Trabanelli S, Onofri C, Aluigi M, Salvestrini V, Ocadlikova D, et al. Indoleamine 2,3-dioxygenase-expressing leukemic dendritic cells impair a leukemia-specific immune response by inducing potent $\mathrm{T}$ regulatory cells. Haematologica. (2010) 95:2022-30. doi: 10.3324/haematol.2010.025924

177. Chamuleau ME, van de Loosdrecht AA, Hess CJ, Janssen JJ, Zevenbergen A, Delwel R, et al. High INDO (indoleamine 2,3-dioxygenase) mRNA level in blasts of acute myeloid leukemic patients predicts poor clinical outcome. Haematologica. (2008) 93:1894-8. doi: 10.3324/haematol.13112

178. Jafarzadeh N, Safari Z, Pornour M, Amirizadeh N, Forouzandeh Moghadam M, Sadeghizadeh M. Alteration of cellular and immune-related properties of bone marrow mesenchymal stem cells and macrophages by K562 chronic myeloid leukemia cell derived exosomes. J Cell Physiol. (2019) 234:3697-710. doi: $10.1002 / j \mathrm{cp} .27142$

179. Gallipoli P, Pellicano F, Morrison H, Laidlaw K, Allan EK, Bhatia RG, et al. et al. Autocrine TNF-alpha production supports CML stem and progenitor cell survival and enhances their proliferation. Blood. (2013) 122:3335-9. doi: 10.1182/blood-2013-02-485607

180. Zhou X, Li Z, Zhou J. Tumor necrosis factor alpha in the onset and progression of leukemia. Exp Hematol. (2017) 45:17-26. doi: 10.1016/j.exphem.2016.10.005

181. Fisher DT, Appenheimer MM, Evans SS. The two faces of IL-6 in the tumor microenvironment. Semin Immunol. (2014) 26:38-47. doi: 10.1016/j.smim.2014.01.008

182. Ghannam S, Bouffi C, Djouad F, Jorgensen C, Noel D. Immunosuppression by mesenchymal stem cells: mechanisms and clinical applications. Stem Cell Res Ther. (2010) 1:2. doi: 10.1186/scrt2

183. Sato K, Ozaki K, Oh I, Meguro A, Hatanaka K, Nagai T, et al. Nitric oxide plays a critical role in suppression of T-cell proliferation by mesenchymal stem cells. Blood. (2007) 109:228-34. doi: 10.1182/blood-2006-02002246

184. Ren G, Zhang L, Zhao X, Xu G, Zhang Y, Roberts AIC, et al. Mesenchymal stem cell-mediated immunosuppression occurs via concerted action of chemokines and nitric oxide. Cell Stem Cell. (2008) 2:141-50. doi: $10.1016 /$ j.stem.2007.11.014

Conflict of Interest: The authors declare that the research was conducted in the absence of any commercial or financial relationships that could be construed as a potential conflict of interest.

Copyright $\odot 2019$ Ciciarello, Corradi, Loscocco, Visani, Monaco, Cavo, Curti and Isidori. This is an open-access article distributed under the terms of the Creative Commons Attribution License (CC BY). The use, distribution or reproduction in other forums is permitted, provided the original author(s) and the copyright owner(s) are credited and that the original publication in this journal is cited, in accordance with accepted academic practice. No use, distribution or reproduction is permitted which does not comply with these terms. 